\title{
Pituitary Adenylate Cyclase-Activating Polypeptide Activates a Phospholipase C-Dependent Signal Pathway in Chick Ciliary Ganglion Neurons that Selectively Inhibits $\alpha 7$-Containing Nicotinic Receptors
}

\author{
Desiree Pardi and Joseph F. Margiotta \\ Department of Anatomy and Neurobiology, Medical College of Ohio, Toledo, Ohio 43614-5804
}

Neuropeptide receptors couple via G-proteins to two principal signaling pathways that elevate cAMP through adenylate cyclase (AC) or mobilize intracellular $\mathrm{Ca}^{2+}$ through phospholipase C (PLC)-stimulated inositol phosphate (IP) turnover and production of inositol 1,4,5-trisphosphate $\left(\mathrm{IP}_{3}\right)$. We showed previously that high-affinity receptors for pituitary adenylate cyclaseactivating polypeptide (PACAP) are present on chick ciliary ganglion neurons and that receptor occupation increases CAMP production, resulting in enhanced acetylcholine sensitivity. After we suppressed AC activity and cAMP production with 2'-5' dideoxyadenosine, however, PACAP no longer increased acetylcholine sensitivity but instead reduced it, suggesting that an AC-independent signal pathway activated by PACAP inhibits some nicotinic acetylcholine receptors (AChRs). We now use fast-perfusion, imaging, and biochemical methods to identify the AChRs modulated by PACAP and to characterize the signal pathway responsible for their inhibition. Without previous $A C$

Neuropeptides serve as trophic factors, co-transmitters, and modulators of ion channel function. An important route of neuropeptide action involves binding to a cell-surface receptor that couples via a membrane-associated G-protein (e.g., $\mathrm{G}_{\mathrm{s}}, \mathrm{G}_{\mathrm{q}}, \mathrm{G}_{\mathrm{i}}$ ) to effector enzymes such as adenylate cyclase (AC) or phospholipase C (PLC) (Ross, 1989; Hille, 1992; Exton, 1996). The resulting changes in second messenger and kinase activities can then exert potent effects on downstream targets, including ion channels (Swope et al., 1993; Levitan, 1994). Our work has explored the regulation of nicotinic acetylcholine receptor (AChR) channels on chick ciliary ganglion neurons. We reported previously that AChR function is enhanced after intracellular cAMP is elevated by application of either cAMP analogs (Margiotta et al., 1987) or AC-stimulating neuropeptides [vasoactive intestinal peptide (VIP) or pituitary adenylate cyclase-activating polypeptide (PACAP)] that increase endogenous cAMP production via PACAP type I receptors (Gurantz et al., 1994; Margiotta and Pardi, 1995). To link the cAMP produced by PACAP to subse-

Received Feb. 2, 1999; revised May 10, 1999; accepted May 17, 1999.

This work was supported by National Institutes of Health Grant NS24417 to J.F.M. Special thanks go to Dr. Diomedes Logothetis for support and advice. We also thank Min Chen for expert technical assistance, and Drs. Joan Brown, Kathleen Dunlap, Marthe Howard, Victor May, and Phyllis Pugh for helpful discussions.

Correspondence should be addressed to Dr. Joseph Margiotta, Department of Anatomy and Neurobiology, Medical College of Ohio, 3035 Arlington Avenue, Toledo, OH 43614-5804.

Dr. Pardi's present address: Department of Medicine, Mount Sinai School of Medicine, 1 Gustave Levy Place, New York, NY 10029.

Copyright (C) 1999 Society for Neuroscience $0270-6474 / 99 / 196327-11 \$ 05.00 / 0$ block, both the rapidly desensitizing, $\alpha$-bungarotoxin ( $\alpha$ Bgt)sensitive $\alpha 7$-AChRs and the slowly desensitizing, $\alpha$ Bgtinsensitive $\alpha 3^{*}$-AChRs on the neurons were potentiated by PACAP. After AC blockade, however, PACAP inhibited $\alpha 7$ AChRs but left $\alpha 3^{*}$-AChRs unaffected. The selective inhibition of $\alpha 7$-AChRs appeared to use a PLC signaling pathway because it was not seen after lowering PLC activity or buffering intracellular $\mathrm{Ca}^{2+}$ and was mimicked by dialyzing neurons with an $\mathrm{IP}_{3}$ receptor agonist. PACAP also induced IP turnover and increased $\left[\mathrm{Ca}^{2+}\right]_{i}$ assessed directly with Fluo-3AM imaging. Given our previous findings that PACAP receptors couple to $A C$, the present results demonstrate a remarkable ability of a single neuropeptide to activate two signaling pathways and in so doing selectively regulate two classes of downstream ion channel targets.

Key words: neuropeptide; acetylcholine; ion channel; modulation; fast perfusion; $\mathrm{Ca}^{2+}$ imaging; whole-cell recording

quent AChR modulation, neurons were pretreated with $\mathrm{AC}$ inhibitors (Margiotta and Pardi, 1995). The pretreatments blocked the ability of PACAP to increase cAMP but, quite surprisingly, reduced the subsequent peak ACh response below control levels. The results suggested that a second PACAP-activated intracellular pathway inhibits AChR function, and the present studies were undertaken to characterize this pathway and identify the AChRs that are affected.

Ciliary ganglion neurons express two AChR classes that differ in subunit composition, pharmacological, and electrophysiological properties. One class contains $\alpha 7$ subunits, which are recognized with high affinity by $\alpha$-bungarotoxin $(\alpha \mathrm{Bgt})$. Membrane currents generated by native $\alpha 7$-AChRs on ciliary or hippocampal neurons or by recombinant chick or rat $\alpha 7$ homo-oligomers expressed in Xenopus oocytes activate and desensitize rapidly and are blocked by $\alpha$ Bgt (Couturier et al., 1990; Alkondon and Albuquerque, 1993; Zhang et al., 1994). The other AChR class on ciliary ganglion neurons ( $\alpha 3^{*}$-AChRs) contains $\alpha 3, \beta 4, \alpha 5$, and (sometimes) $\beta 2$ subunits, but not $\alpha 7$ subunits, and is not recognized by $\alpha$ Bgt (Vernallis et al., 1993; Conroy and Berg, 1995). Whole-cell currents generated by rapidly perfusing the neurons with $20 \mu \mathrm{M}$ nicotine feature two distinct components. The large, initial component is mediated by $\alpha 7$-AChRs because it displays rapid onset and desensitization kinetics and is $\alpha \mathrm{Bgt}$ sensitive, whereas the smaller component is mediated by $\alpha 3^{*}$-AChRs because it activates and desensitizes more slowly and is predominantly $\alpha \mathrm{Bgt}$ insensitive (Zhang et al., 1994; Blumenthal et al., 1999). 
Evidence from other systems demonstrates that PACAP type I receptors can couple to both AC and PLC (Rawlings, 1994). PLC-dependent signaling would be expected to produce inositol phosphate (IP) turnover culminating in inositol 1,4,5trisphosphate $\left(\mathrm{IP}_{3}\right)$-dependent mobilization of $\left[\mathrm{Ca}^{2+}\right]_{\mathrm{i}}$ (Hille, 1992). Thus the observation that AC block unmasks an inhibition of ACh sensitivity suggests that AC and PLC signals normally interact to achieve balanced ACh sensitivity. The present findings confirm that PACAP type I receptors couple to both AC-and PLC-dependent pathways and demonstrate that the AC pathway produces PKA-dependent enhancement of both $\alpha 3^{*}$ - and $\alpha 7$ AChRs, whereas the PLC pathway produces a $\mathrm{Ca}^{2+}$-dependent inhibition of $\alpha 7$-AChRs.

A preliminary account of these results has been published previously (Pardi and Margiotta, 1996).

\section{MATERIALS AND METHODS}

Cell and substrate preparation. Neurons were dissociated from embryonic chick ciliary ganglia using collagenase A treatment $(0.3 \mathrm{mg} / \mathrm{ml}$ for $20 \mathrm{~min}$ at $37^{\circ} \mathrm{C}$ ) and mechanical trituration as described previously (Margiotta and Gurantz, 1989) and plated on glass or plastic substrates coated with poly-D-lysine. Embryonic day 13 (E13) or E14 neurons were used in most experiments because they can be isolated with $>80 \%$ recovery and express high levels of both AChRs and PACAP type I receptors (Margiotta and Gurantz, 1989; Margiotta and Pardi, 1995). For electrophysiological and imaging experiments, the neurons were dissociated and plated at a density of one ganglion equivalent $\left(\sim 3-4 \times 10^{3}\right.$ neurons) per glass coverslip (12 mm diameter) (Fisher Scientific, Houston, TX) in the following recording solution (in $\mathrm{mM}$ ): $145.0 \mathrm{NaCl}, 5.3 \mathrm{KCl}, 5.4 \mathrm{CaCl}_{2}$, $0.8 \mathrm{MgSO}_{4}, 5.6$ glucose, and 5.0 HEPES, $\mathrm{pH} 7.4$, containing $10 \%(\mathrm{v} / \mathrm{v})$ heat-inactivated horse serum. Neurons attached to the substrate within $30 \mathrm{~min}$ and were maintained at $37^{\circ} \mathrm{C}$ for $1-2 \mathrm{hr}$ before use. For IP turnover measurements, dissociated neurons from E12 embryos were plated on coated tissue culture wells ( $24 \mathrm{~mm}$ diameter; Falcon) at two to six ganglion equivalents per well and maintained at $37^{\circ} \mathrm{C}$ in $95 \%$ air $/ 5 \%$ $\mathrm{CO}_{2}$ in culture medium containing myo- $\left[{ }^{3} \mathrm{H}\right]$ inositol for $16-24 \mathrm{hr}$ (see below). The culture medium consisted of MEM (no. 11090-08) supplemented with $100 \mathrm{U} / \mathrm{ml}$ penicillin, $100 \mu \mathrm{g} / \mathrm{ml}$ streptomycin, $2 \mathrm{~mm}$ glutamine, and $10 \%$ (vol/vol) heat-inactivated horse serum (all components from Life Technologies-BRL, Rockville, MD).

To coat glass coverslips, they were first acid-washed, then treated with poly-D-lysine in $0.13 \mathrm{M}$ borate buffer, $\mathrm{pH} 8.5$, washed four times with distilled water, and air-dried. For electrophysiological experiments, 70$150 \mathrm{kDa}$ poly-D-lysine (P-0899; Sigma, St. Louis, MO) was applied to coverslips at $1 \mu \mathrm{g} / \mathrm{ml}$ for $1 \mathrm{~min}\left(21-23^{\circ} \mathrm{C}\right)$. With this minimal coating protocol, the neuron cell bodies became loosely attached, which allowed them to be lifted above the substrate for agonist exposure during fast perfusion experiments (see below). For $\mathrm{Ca}^{2+}$ imaging and IP turnover experiments, stronger neuron attachment was achieved by coating glass coverslips or tissue culture wells with $\geq 300 \mathrm{kDa}$ poly-D-lysine (P-1024, Sigma) at $1 \mathrm{mg} / \mathrm{ml}$ for $12-16 \mathrm{hr}\left(4^{\circ} \mathrm{C}\right)$.

Electrophysiology. Coverslips were placed in a lucite chamber (model RC-25F, Warner Instruments, Hamden, CT) on the stage of an Olympus CK2 inverted microscope, and the neurons were viewed with Hoffman modulation contrast optics using a $40 \times(0.5 \mathrm{NA})$ long working distance objective. The chamber volume was maintained at $\sim 200 \mu \mathrm{l}$ and continuously perfused at $\sim 2 \mathrm{ml} / \mathrm{min}$ from one of two $30 \mathrm{ml}$ syringes that contained recording solution or recording solution plus test reagent (e.g., $\alpha$ Bgt, PACAP, VIP) at room temperature $\left(21-23^{\circ} \mathrm{C}\right)$. The syringes were controlled with stopcocks and connected to the chamber via a perfusion manifold (Model MP-4, Warner Instruments). Patch recording pipettes were pulled from Corning 8161 glass tubing $[1.5 \mathrm{~mm}$ outer diameter (o.d.)] and had tip impedances of 1-2 $\mathrm{M} \Omega$ when filled with internal solution containing (in $\mathrm{mM}$ ): $145.6 \mathrm{CsCl}, 1.2 \mathrm{CaCl}_{2}, 2$ EGTA, 15.4 glucose, 1 ATP, and 5 Na-HEPES, pH 7.3. Nicotine was dissolved in recording solution and applied by fast microperfusion (Zhang et al., 1994; Jonas, 1995) using solution streams delivered by laminar gravity flow from the channels of glass $\theta$-tubing (1.6 mm o.d.; BT-150-10, Sutter Instruments, Novato, CA) pulled to an overall o.d. of $\sim 100-120 \mu \mathrm{m}$. The $\theta$-tubing was mounted to a piezoelectric device (Burleigh Instruments, model LSS-3100) that provided rapid movement steps and was controlled by an amplifier/driver (Burleigh Instruments, model PZ-150M) and trig- gered by the recording software. To achieve fast perfusion, an "on-cell" seal with resistance $\geq 10 \mathrm{G} \Omega$ was first formed on a loosely attached neuron, which was then gently lifted off the substrate. A whole-cell configuration (Hamill et al., 1981) was then established, and the neuron was manipulated into the control recording solution stream flowing from the $\theta$-tubing. After capacitance compensation and testing for sodium currents (see below), the stream bathing the neuron was rapidly switched to $20 \mu \mathrm{M}$ nicotine for $3 \mathrm{sec}$ and then switched back to recording solution. With use of these devices, junction current experiments with open tip patch pipettes containing $150 \mathrm{~mm} \mathrm{CsCl}$ reveal that movement of the interface separating streams of 150 and $75 \mathrm{~mm} \mathrm{NaCl}$ occurred in $<1$ msec.

Neuronal responses induced by fast microperf usion with nicotine were assessed in whole-cell mode at a holding potential $\left(V_{\mathrm{h}}\right)$ of $-70 \mathrm{mV}$ as described previously (Margiotta and Gurantz, 1989; Zhang et al., 1994). Membrane currents were collected with an Axopatch 1B amplifier (Axon Instruments, Burlingame, CA) and digitized using a TL-1 interface controlled by pClamp 6.0 software (Axon Instruments). For capacity compensation, series resistance measurement, and evaluation of sodium channels, the currents were filtered and digitized at $10 \mathrm{kHz}$. AChR currents were filtered at $1 \mathrm{kHz}$ and digitized at $1-2 \mathrm{kHz}$. After achieving the whole-cell configuration, membrane capacitance compensation was achieved by eliminating the capacitive current transient in response to a $-10 \mathrm{mV}$ pulse using the amplifier series resistance $\left(R_{\mathrm{s}}\right)$ and capacitance $\left(C_{\mathrm{m}}\right)$ controls, thereby obtaining a measure of $R_{\mathrm{s}}$. For most cells, $R_{\mathrm{s}}$ was measured both before and after fast perfusion with nicotine. Data from cells in which the average $R_{\mathrm{s}}$ exceeded $4 \mathrm{M} \Omega$ were not analyzed further. Because $R_{\mathrm{s}}$ was usually $\leq 3 \mathrm{M} \Omega$, peak nicotine-induced currents (approximately $-7000 \mathrm{pA}$ ) generated a voltage deviation $\left(V_{\mathrm{s}}\right)$ from the applied holding potential no larger than $-21 \mathrm{mV}$. In such cases, the actual holding potential $\left(V_{\mathrm{h}}-V_{\mathrm{s}}=-49 \mathrm{mV}\right)$ was well below that for activating sodium currents (see below). Recordings were corrected for $R_{\mathrm{s}}$ errors using one of two approaches, both of which gave similar results. For some recordings, $60-80 \%$ compensation was achieved with the patch-clamp controls, just before the nicotine trial. In other cases, current values were adjusted off-line for errors in holding potential as described previously (Margiotta and Gurantz, 1989), assuming an AChR reversal potential $\left(E_{\mathrm{r}}\right)$ of $-11 \mathrm{mV}$. Briefly stated, each measured current value was multiplied by a factor $\omega$ representing the ratio of the voltage gradient across the AChR under conditions of zero and finite series resistance voltage error $\left(\omega=\left(V_{\mathrm{h}}-E_{\mathrm{r}}\right) /\left(V_{\mathrm{h}}-E_{\mathrm{r}}-V_{\mathrm{s}}\right)\right)$. Although the $R_{\mathrm{s}}$ correction allowed more accurate measurement of individual nicotine-induced whole-cell currents, the general conclusions presented here were not significantly changed when the results were reanalyzed without the correction. To test for adequate access, sodium currents were induced by applying a family of test depolarizations from -40 to $+30 \mathrm{mV}$ in $5 \mathrm{mV}$ increments. Sodium current activation occurred in a voltage range from -25 to $0 \mathrm{mV}$. Cells in which sodium currents activated late or displayed discontinuities in their rising or falling phases were not studied further.

Whole-cell AChR currents induced by fast nicotine perfusion activated rapidly to a peak value $\left(I_{\mathrm{p}}\right)$ and then decayed with complex kinetics caused by the contribution of distinct AChR classes having different rates of desensitization (Zhang et al., 1994; Vijayaraghavan et al., 1995). The nicotine-induced current at time $t\left(I_{\mathrm{t}}\right)$ from $I_{\mathrm{p}}(t=0)$ was well characterized by fitting to the data the sum of two to three exponential functions given by $I_{\mathrm{t}}=A_{\mathrm{f}} \exp \left(-\mathrm{t} / \tau_{\mathrm{f}}\right)+A_{\mathrm{i}} \exp \left(-\mathrm{t} / \tau_{\mathrm{f}}\right)+A_{\mathrm{s}} \exp \left(-\mathrm{t} / \tau_{\mathrm{f}}\right)+$ $C$ using a Simplex algorithm included in pClamp. $A_{\mathrm{f}}, A_{\mathrm{i}}$, and $A_{\mathrm{s}}$ indicate the amplitudes of the fast, intermediate, and slow current components, $\tau_{\mathrm{f}}$, $\tau_{\mathrm{i}}$, and $\tau_{\mathrm{s}}$ represent their respective decay time constants, and $C$ represents the amplitude of the nondecaying current. The algorithm usually converged within $10^{3}$ iterations and produced fits with associated errors $<80 \mathrm{pA}$ (typically $<2 \%$ of $I_{\mathrm{p}}$ ). Because we were most interested here in the fast component, its amplitude $\left(I_{\mathrm{f}}\right)$ was estimated both from the fit value $\left(A_{\mathrm{f}}\right)$ and by subtracting the summed slower component amplitudes $\left(I_{\mathrm{s}}=A_{\mathrm{i}}+A_{\mathrm{s}}+C\right)$ from the decaying peak current $\left(I_{\mathrm{p}}\right)$. $I_{\mathrm{f}}$ values presented here were obtained using the latter method and were within $10 \%$ of those obtained using the former approach. Component current values were normalized for differences in cell size by dividing $I_{\mathrm{p}}, I_{\mathrm{f}}$, and $I_{\mathrm{s}}$ values by the membrane capacitance $\left(C_{\mathrm{m}}\right)$ determined from the patchclamp controls. The change in agonist response for neurons in the test condition was determined by comparing normalized current amplitude values with neurons in control conditions from the same experiment. The statistical significance of any changes $(p<0.05)$ was determined using Student's unpaired $t$ test. 
Inositol phosphate release assay. The coupling of type I PACAP receptors to IP turnover was assessed using an approach similar to that described by Rathouz et al. (1995). Neurons were incubated at $37^{\circ} \mathrm{C}$ in culture medium containing $2 \mu \mathrm{Ci} / \mathrm{ml} m y o-\left[{ }^{3} \mathrm{H}\right]$ inositol (NEN/DuPont, Wilmington, DE) (specific activity $\sim 19 \mathrm{mCi} / \mathrm{mmol}$ ) for $16-24 \mathrm{hr}$, washed three times in MEM containing $50 \mathrm{~mm} \mathrm{LiCl}$, and equilibrated a final 20 min in the same buffer at $37^{\circ} \mathrm{C}$. Test peptides were then added from frozen stocks to duplicate or quadruplicate wells, and the cells were incubated for $50-60 \mathrm{~min}$ at $37^{\circ} \mathrm{C}$. In some cases neurons were preincubated for 20 min with indicated concentrations of AC or PLC inhibitor before peptide addition. Reactions were stopped by placing the cultures on ice, followed by addition of 0.5 vol ice-cold methanol. Cells were scraped from the wells, the lipids were extracted with chloroform and water $(0.5: 0.4, \mathrm{v} / \mathrm{v})$, and an aliquot of the chloroform phase was taken to determine the extent of incorporation of label into IPs. The aqueous layer was transferred to a tube containing $300 \mathrm{mg}$ of the anion exchange resin AG-1X8 (formate form), vortexed briefly, and incubated at room temperature for $20 \mathrm{~min}$. After rapid centrifugation, the liquid phase was removed, and an aliquot was counted in a scintillation counter to determine the amount of label remaining as free inositol. The resin was rinsed three times with water and then incubated for $30 \mathrm{~min}$ with $1 \mathrm{ml}$ of ice-cold $2 \mathrm{M}$ ammonium formate $/ 0.1 \mathrm{M}$ formic acid, the tubes were centrifuged briefly, and $10 \mathrm{ml}$ of scintillation fluid was added to the eluate for counting. Specific counts from each individual sample well for a given condition were averaged. For each peptide dose, the change in total IPs was determined as the average of the counts in the presence of peptide minus the average of counts in the absence of peptide, and the data were fit by nonlinear regression using Prism version 2.0 (GraphPad Software, San Diego, CA).

Calcium imaging. After a $1 \mathrm{hr}$ incubation at $37^{\circ} \mathrm{C}$, cells were loaded with the calcium indicator dye Fluo-3AM (1 $\mu \mathrm{M}$; Molecular Probes, Eugene, OR) (Kao et al., 1989) in recording solution (see description of solutions) for $45 \mathrm{~min}$ at room temperature in the dark. Cells were then washed three times with recording solution and maintained in darkness until use. Neurons were examined with reflected light fluorescence optics using an Olympus BX50 microscope equipped with a $40 \times$ water immersion objective (Uplan Fl 40×, 0.8 N.A.). Excitation light from a $100 \mathrm{~W}$ mercury lamp was passed through a 450-480 nm bandpass filter, reflected from a $500 \mathrm{~nm}$ dichroic mirror, and focused through the objective onto the neurons. The emitted light passed through the objective and dichroic mirror and was observed using a standard $515 \mathrm{~nm}$ barrier filter set. The bath was continuously perfused by gravity flow at $\sim 2 \mathrm{ml} / \mathrm{min}$, and solutions were switched manually between control and peptide tests just after the shutter was opened. In some cases, neurons were clamped in whole-cell mode using patch pipettes filled with intracellular solution containing $200 \mu \mathrm{M} 2^{\prime}-5^{\prime}$ dideoxyadenosine (ddA), with or without other test compounds. For each trial, a sequence of 12-15 eight-bit images covering time before, during, and after application of test solutions was captured using a cooled digital CCD camera (SENSYS; Photometrics, Tucson AZ) under the control of IP Lab software (v 3.0 Scanalytics, Reading, PA). For analysis and quantitation, the Fluo-3AM fluorescence signals were corrected for variability in dye loading and path length by normalizing to the baseline fluorescence $\left(F_{0}\right)$ as described previously (Cornell-Bell et al., 1990; Vijayaraghavan et al., 1992). The change in fluorescence intensity $\left(\Delta F=F-F_{0}\right)$ relative to $F_{0}$ was determined from ellipsoid regions of interest (ROIs) overlaid on each neuron somata in a field (one to five neurons per field). As a criterion, neurons displaying $\Delta F / F_{0} \geq 0.15$ during the $30-90 \mathrm{sec}$ of peptide application were scored as responsive. By this criterion, $85 \%$ of 67 neurons tested responded to application of $100 \mathrm{~nm}$ PACAP38 with an increase in $\left[\mathrm{Ca}^{2+}\right]_{\mathrm{i}}$. For other test conditions, the sample size required for the proportion of responsive neurons to be significantly different $(p<0.05)$ from 0.85 was estimated using the equation for comparing two independent proportions (Motulsky, 1995), with $\alpha=0.05$ and $\beta=0.2$. Digitized image frames were manipulated for presentation using Photoshop (v 4.0.1; Adobe Systems, Inc.) after conversion to TIFF format.

Materials. Fertilized White Leghorn chicken eggs were obtained from Hertzfeld Poultry Farm (Waterville, $\mathrm{OH}$ ) and maintained at $37^{\circ} \mathrm{C}$ in a forced-air draft incubator at $100 \%$ humidity. PACAP38, PACAP27, and VIP were obtained from the American Peptide Company (San Diego, Ca). Glucagon was obtained from Peninsula Laboratories (Belmont, CA). $\alpha$ Bgt, ddA, D-myo-inositol 1,4,5,-trisphosphate, 3-deoxy-, hexasodium salt (HA-IP $\mathrm{H}_{3}$ ), D-myo-inositol 1,4,5,-trisphosphate, 2,3,6-trideoxy-, hexasodium salt $\left(\mathrm{LA}-\mathrm{IP}_{3}\right),\{N-[2-((p$-bromocinnamyl $)$ amino $)$ ethyl $]-5-$ isoquinolinesulfonamide, $\mathrm{HCl}\}$ (H-89), Ruthenium Red, and \{1-[6-
((17 $\beta$-3-methoxyestra-1,3,5(10)-trien-17-yl)amino)hexyl]-1H-pyrrole2,5-dione (U-73122) were all purchased from Calbiochem (La Jolla, CA). All other reagents were obtained from Sigma.

\section{RESULTS PACAP differentially regulates $\alpha 7-$ and $\alpha 3^{*}$-AChRs}

We previously reported a dual action for PACAP on neuronal nicotinic AChR function (Margiotta and Pardi, 1995). Application of the peptide to ciliary ganglion neurons normally increased cAMP production and subsequent ACh sensitivity but led to reduced $\mathrm{ACh}$ sensitivity when the neurons were pretreated with AC inhibitors (ddA or SQ-5536) to limit cAMP production. To identify the AChR subtypes modulated by exposure to PACAP and to further characterize the relevant signaling mechanisms, we incorporated fast nicotine perfusion, a method that allows wholecell currents activated by the two major classes of AChRs on the neurons to be distinguished on the basis of differences in component amplitudes and desensitization kinetics (Zhang et al., 1994; Blumenthal et al., 1999). Neurons pretreated with ddA displayed a large inward current in response to fast perfusion with $20 \mu \mathrm{M}$ nicotine that activated to peak value $\left(I_{\mathrm{p}}\right)$ within $2-5$ msec and subsequently desensitized with kinetics that could be described by the sum of two or three exponential functions (Fig. 1A) (see Materials and Methods). The large-amplitude initial current $\left(I_{\mathrm{f}}\right)$ decayed rapidly $\left(\tau_{\mathrm{f}}=1-10 \mathrm{msec}\right)$ and was accompanied by one to two smaller components that decayed more slowly $\left(\tau_{\mathrm{i}}=0.1-0.4 \mathrm{sec} ; \tau_{\mathrm{s}}=0.4-12.0 \mathrm{sec}\right)$. The fast current component of the nicotine response $\left(I_{\mathrm{f}}\right)$ is likely to represent activation of $\alpha 7$-AChRs. Exposure to $\alpha \mathrm{Bgt}$, a toxin that specifically recognizes $\alpha 7$-AChRs on ciliary ganglion neurons and blocks their function, abolished $I_{\mathrm{f}} / C_{\mathrm{m}}$ in all of the 13 neurons tested (Fig. $1 B$ ), reducing $I_{\mathrm{p}} / C_{\mathrm{m}}$ by $>80 \%$. In contrast, the slow current components are likely to primarily represent activation of $\alpha 3^{*}$-AChRs because $I_{\mathrm{s}} / C_{\mathrm{m}}$ was not detectably different $(p>0.1)$ in 22 control and 9 $\alpha$ Bgt-treated neurons $(-60 \pm 6$ and $-51 \pm 5 \mathrm{pA} / \mathrm{pF}$, respectively). In addition, the slow current desensitization kinetics $\left(\tau_{\mathrm{i}}, \tau_{\mathrm{s}}\right)$ were not detectably changed after exposure to $\alpha \operatorname{Bgt}(p>0.1$ for each). Thus the whole-cell fast perfusion method permits identification of currents produced by activation of $\alpha 7$ - and $\alpha 3^{*}$ AChRs, the two major nicotinic receptor classes on chick ciliary ganglion neurons.

Whole-cell nicotine response parameters obtained from neurons pretreated with ddA $(200 \mu \mathrm{M}, 2-5 \mathrm{~min})$ (Table 1) were indistinguishable from those obtained from untreated neurons tested in parallel (Fig. 1D). When the ddA pretreatment was followed by treatment with PACAP38 (100 nM, $10 \mathrm{~min})$ to maximally occupy PACAP type I receptors, however, the subsequent nicotine-induced $\alpha 7$-AChR current was reduced compared with control neurons pretreated with ddA alone (Fig. 1, compare $A$, $C)$. The inhibition was specific for $\alpha 7$-AChRs because $I_{\mathrm{f}} / C_{\mathrm{m}}$ was significantly reduced, whereas $I_{\mathrm{s}} / C_{\mathrm{m}}$ representing $\alpha 3^{*}$-AChRs was unchanged (Table 1 ). Percentage changes in $I_{\mathrm{f}} / C_{\mathrm{m}}$ for neurons treated with high- or low-affinity type I receptor ligands relative to ddA controls tested in parallel are compiled in Figure 1D. PACAP38 and PACAP27 significantly reduced $I_{\mathrm{f}} / C_{\mathrm{m}}$ by similar amounts $(55 \pm 10 \%$ and $40 \pm 9 \%$, respectively; $p<0.05$ for both), whereas neither peptide detectably changed the slower $\alpha 3^{*}$-AChR current component $I_{\mathrm{s}} / C_{\mathrm{m}}(p>0.1$ for both). No significant inhibition was observed for VIP, a low-affinity PACAP type $\mathrm{I}$ receptor ligand $\left(\mathrm{IC}_{50} \sim 1 \mu \mathrm{M}\right) . I_{\mathrm{f}} / C_{\mathrm{m}}$ was unchanged in neurons treated with $100 \mathrm{nM}$ VIP, and although $1 \mu \mathrm{M}$ VIP produced an apparent $20 \%$ inhibition, the effect was not statisti- 
A ddA Control

$20 \mu \mathrm{M}$ Nicotine

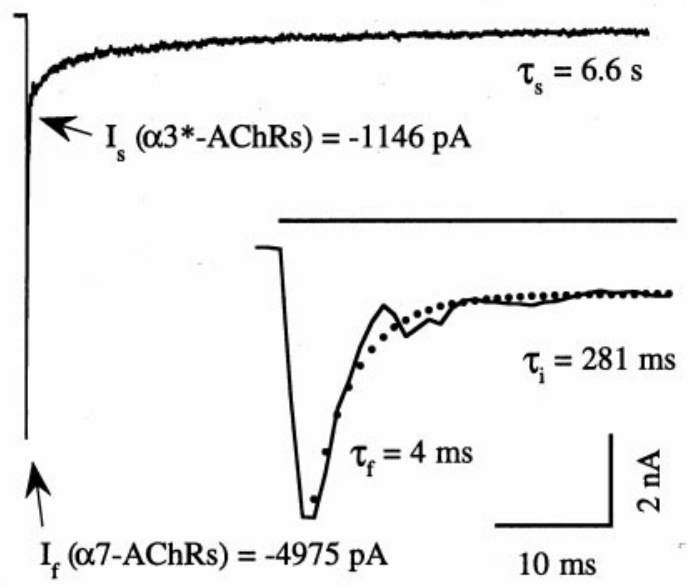

B

$60 \mathrm{nM} \alpha-\mathrm{Bgt}$
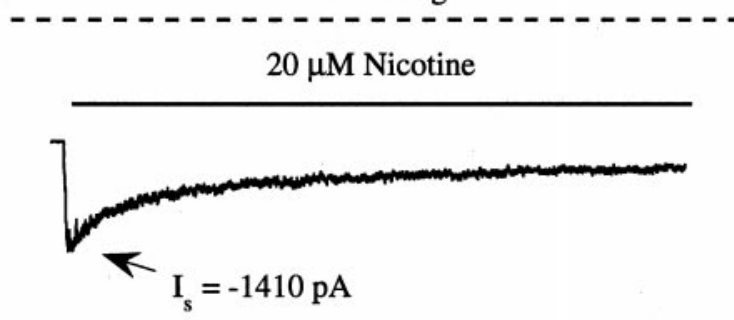

C ddA then PACAP38
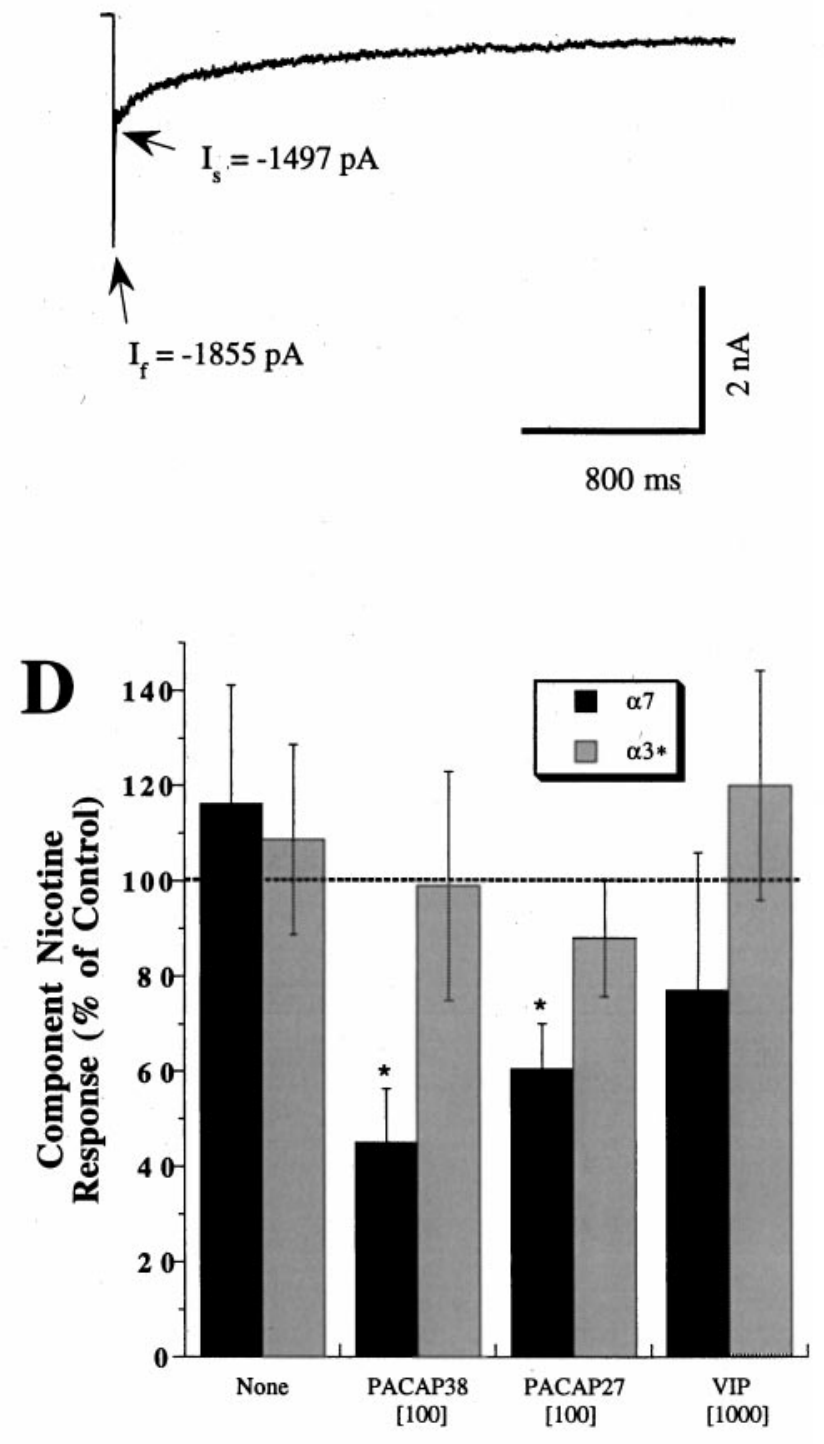

Peptide Treatment [nM]

Figure 1. PACAP selectively inhibits $\alpha 7$-AChR currents when AC activity is suppressed. $A-C$, Representative whole-cell current records are displayed from separate E13 and E14 ciliary ganglion neurons held at $-70 \mathrm{mV}$ and exposed to $20 \mu \mathrm{M}$ nicotine for $\sim 3$ sec by fast perfusion, as indicated by the solid bar. All neurons were pretreated with $200 \mu \mathrm{M}$ ddA for 1-7 min to inhibit AC as described in Materials and Methods. Arrows labeled $I_{\mathrm{f}}$ and $I_{\mathrm{s}}$ indicate peak values of the $\alpha 7$ - and $\alpha 3^{*}$-AChR current components, respectively. Calibration bars in $C$ apply to $A-C$. $A$, Response to $20 \mu \mathrm{M}$ nicotine application from a control neuron $\left(C_{\mathrm{m}}=23 \mathrm{pF}\right)$ features a rapidly activating current reaching a peak value $\left(I_{\mathrm{p}}\right)$ of $-6121 \mathrm{pA}$ and decaying with complex kinetics. The rapidly activating and desensitizing part of the response is shown on an expanded time scale in the inset, showing the superimposed fit to the equation in Materials and Methods (dots) and the associated values of $\tau_{\mathrm{f}}$ and $\tau_{\mathrm{i}}\left(\tau_{\mathrm{s}}\right.$ shown above). Similar nicotine responses were obtained in the presence of $1 \mu \mathrm{M}$ TTX and $10 \mu \mathrm{M} \mathrm{CdCl}$ (J. Margiotta, unpublished observations), indicating that they arise from nicotinic AChRs rather than from voltage-dependent $\mathrm{Na}^{+}$or $\mathrm{Ca}^{2+}$ channels (Zhang et al., 1994). $B$, Nicotine response from a neuron $\left(C_{\mathrm{m}}=28 \mathrm{pF}\right)$ incubated with $60 \mathrm{nM} \alpha \mathrm{Bgt}$ beginning $2 \mathrm{hr}$ before, and continuing throughout, the ddA pretreatment and recording (dashed bar). Note that the fast component is abolished by $\alpha \mathrm{Bgt}$, indicating that it arises from $\alpha 7$-AChRs. $C$, Nicotine response from a neuron $\left(C_{\mathrm{m}}=25 \mathrm{pF}\right)$ treated with $100 \mathrm{~nm}$ PACAP38 for 6 min after the ddA pretreatment. Note that the PACAP3 8 treatment reduced the $\alpha 7$-AChR component $\left(I_{\mathrm{f}}\right)$, leaving the $\alpha 3^{*}$-AChR component $\left(I_{\mathrm{s}}\right)$ unaffected. $D$, Summary of the percentage change (mean $\pm \mathrm{SEM})$ in the $\alpha 7-\mathrm{AChR}\left(I_{\mathrm{f}} / C_{\mathrm{m}}\right)$ and $\alpha 3^{*}$-AChR $\left(I_{\mathrm{s}} / C_{\mathrm{m}}\right)$ response components after treatment with neuropeptides. Each bar is based on nicotine responses like those in $A$ and $C$ where the individual fast and slow current components indicated by the black and gray bars, respectively, were determined as described above for the indicated peptide treatment $(n=6-19$ for each concentration). Results are expressed as a percentage of the component nicotine responses obtained from the same number of control neurons tested (Figure legend continues) 
Table 1. Effect of PACAP38 on neuronal nicotinic response parameters

\begin{tabular}{|c|c|c|c|c|c|c|}
\hline Condition & $C_{\mathrm{m}}(\mathrm{pF})$ & $I_{\mathrm{f}} / C_{\mathrm{m}}(\mathrm{pA} / \mathrm{pF})$ & $\tau_{\mathrm{f}}(\mathrm{msec})$ & $I_{\mathrm{s}} / C_{\mathrm{m}}(\mathrm{pA} / \mathrm{pF})$ & $\tau_{\mathrm{i}}(\mathrm{msec})$ & $\tau_{\mathrm{s}}(\mathrm{sec})$ \\
\hline ddA (all) & $30 \pm 1(43)$ & $-198 \pm 16(43)$ & $9 \pm 1(43)$ & $-81 \pm 10(43)$ & $173 \pm 25(29)$ & $1.4 \pm 0.3(37)$ \\
\hline $\mathrm{ddA}+\mathrm{PACAP} 38$ & $29 \pm 1(19)$ & $-90 \pm 13(19)^{*}$ & $6 \pm 2(19)$ & $-63 \pm 8$ & $153 \pm 32(16)$ & $1.1 \pm 0.2(17)$ \\
\hline
\end{tabular}

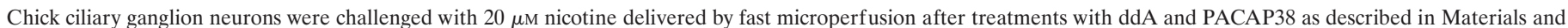

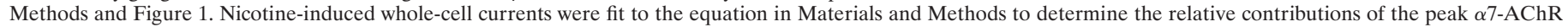

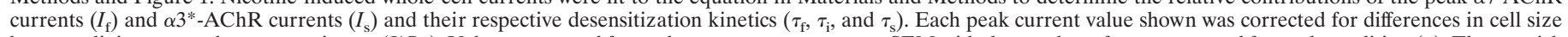

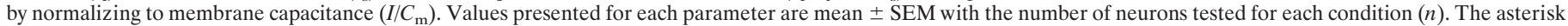

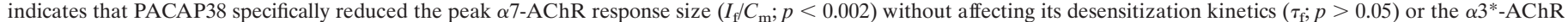
response size $\left(I_{\mathrm{s}} / C_{\mathrm{m}}\right)$ or desensitization properties $\left(\tau_{\mathrm{i}}\right.$ and $\tau_{\mathrm{s}} ; p>0.1$ for each). Note that not all neurons displayed both intermediate and slow decay kinetics.

cally significant ( $p>0.1 ; n=4$ neurons). Neither of the VIP concentrations that was tested detectably altered $I_{\mathrm{s}} / C_{\mathrm{m}}$ (Fig. $1 D$ ). PACAP38 appeared to reduce $\tau_{\mathrm{f}}$ somewhat (Table 1 ); however, the kinetics of desensitization reflected in values of $\tau_{\mathrm{f}}, \tau_{\mathrm{i}}$, and $\tau_{\mathrm{s}}$ were not significantly altered in neurons treated with either of the PACAPs when compared with control neurons tested in parallel ( $p>0.05$ for each; $n=4-17$ treated and control neurons). These findings indicate that occupation of PACAP type I receptors by high-affinity ligands leads to selective inhibition of $\alpha 7$-AChRs and suggest that the inhibition does not involve a change in AChR desensitization.

A similar approach was used to examine the ability of PACAP to regulate $\alpha 7$ - and $\alpha 3^{*}$-AChR currents when the ddA pretreatment was omitted, allowing $\mathrm{AC}$ activity to remain intact and PACAP receptor activation to maximally stimulate cAMP production (Margiotta and Pardi, 1995). Under such conditions, and in accord with previous observations (Margiotta et al., 1987; Margiotta and Pardi, 1995), PACAP38 treatment (100 nM, 5 min) significantly increased both $\alpha 7$ - and $\alpha 3 *$-AChR current components of the subsequent response to $20 \mu \mathrm{M}$ nicotine by approximately twofold (Fig. 2). In addition to involving an increase in cAMP, the ability of PACAP to enhance both the $\alpha 7$ - and $\alpha 3^{*}$-AChR currents is likely to require downstream activation of protein kinase A (PKA), because 5 min preincubation with the PKA inhibitor H-89 $(10 \mu \mathrm{M})$ blocked the increases in both $I_{\mathrm{f}} / \mathrm{C}_{\mathrm{m}}$ and $I_{\mathrm{s}} / \mathrm{C}_{\mathrm{m}}$. The upregulation of $\alpha 3^{*}$ - and $\alpha 7$-AChRs produced by PACAP in ciliary ganglion neurons is consistent with relatively slow peptide receptor activation of a cAMP- and PKA-dependent signaling cascade rather than with rapid AChR modulation expected from membrane-delimited direct G-protein interaction, as reported previously for rat intracardiac neurons (Cuevas and Adams, 1996). We nevertheless tested for rapid modulatory effects by comparing $\alpha 3^{*}$ - and $\alpha 7-\mathrm{AChR}$ responses induced by nicotine $(20 \mu \mathrm{M})$ plus PACAP38 $(100 \mathrm{nM})$ with those induced by nicotine alone. In such experiments, however, the $\alpha 3{ }^{*}$ - and $\alpha 7$ AChR responses were not significantly different under the two conditions (Fig. 3, left). Negative results were also obtained after pretreating the neurons with ddA $(200 \mu \mathrm{M}, 10 \mathrm{~min})$ to block AC (Fig. 3, right). Taken together, these findings indicate that PACAP receptor activation leads to differential regulation of $\alpha 7$ - and $\alpha 3^{*}$-AChRs, occurring over the course of minutes, that depends on the availability of the AC signaling pathway. PACAP enhances the function of both $\alpha 7$ - and $\alpha 3 *$-AChRs when AC is active, causing cAMP to increase and subsequently activate PKA but selectively inhibits $\alpha 7$-AChR function after AC activity is sup- pressed. We next focused on defining the latter, cAMPindependent signaling pathway activated by PACAP that leads to $\alpha 7$-AChR inhibition.

\section{The ability of PACAP to inhibit $\alpha 7-A C h R$ function is $\mathrm{Ca}^{2+}$ dependent}

A previous report suggested that free intracellular calcium $\left[\mathrm{Ca}^{2+}\right]_{\mathrm{i}}$ might play a role in inhibiting $\alpha 7$-AChR function (Vijayaraghavan et al., 1995). We therefore examined the involvement of $\left[\mathrm{Ca}^{2+}\right]_{\mathrm{i}}$ in PACAP38-mediated $\alpha 7$-AChR inhibition by including BAPTA in the patch pipette to buffer $\left[\mathrm{Ca}^{2+}\right]_{\mathrm{i}}$. The presence of BAPTA specifically abolished PACAP's ability to subsequently inhibit $\alpha$-AChRs (Fig. 4). As in Figure 1 and Table 1, $\alpha 7$-AChR currents from ddA-pretreated/PACAP-treated neurons dialyzed with standard intracellular solution were attenuated compared with neurons not exposed to peptide. When ddA-pretreated neurons were dialyzed with intracellular solution containing $10 \mathrm{~mm}$ BAPTA and then treated with 100 nM PACAP38, however, subsequent $\alpha 7-\mathrm{AChR}$ responses were indistinguishable from those obtained from neurons not exposed to PACAP38. As reported previously (Zhang et al., 1994), including BAPTA in the recording pipette did not alter nicotine-evoked currents in control neurons not exposed to ddA or PACAP ( $n=3$ neurons) but did reduce $\mathrm{Ca}^{2+}$ elevation in response to application of $20 \mu \mathrm{M}$ nicotine or $60 \mathrm{~mm} \mathrm{KCl}$ (data not shown). These findings indicate that the signaling pathway, recruited after PACAP receptor activation, increases free $\left[\mathrm{Ca}^{2+}\right]_{\mathrm{i}}$ as a requirement for subsequent $\alpha 7$-AChR inhibition.

\section{PACAP releases $\mathrm{Ca}^{2+}$ from an $\mathrm{IP}_{3}$-sensitive intracellular store}

Many G-protein-coupled receptors are known to increase $\left[\mathrm{Ca}^{2+}\right]_{\mathrm{i}}$ by stimulating PLC, thereby initiating IP turnover that culminates in the generation of $\mathrm{IP}_{3}$, a soluble intracellular messenger (Hille, 1992; Exton, 1996). $\mathrm{IP}_{3}$ can then bind to a receptor on the endoplasmic reticulum membrane, stimulating the release of calcium into the cytoplasm (Berridge, 1993, 1997). Because elevated $\left[\mathrm{Ca}^{2+}\right]_{\mathrm{i}}$ was required for PACAP to inhibit $\alpha 7-\mathrm{AChRs}$, the ability of PACAP38 and related peptides to raise $\left[\mathrm{Ca}^{2+}\right]_{\mathrm{i}}$ was tested using imaging methods after loading the neurons with a calcium indicator dye (Fluo-3AM). In typical experiments, the whole-cell recording configuration was established on dye-loaded neurons using patch pipettes filled with intracellular solution containing ddA, and the bath then was perfused with recording solutions containing PACAP38 (Fig. $5 A$ ). Neurons loaded with

\section{$\leftarrow$}

in parallel that were treated with ddA alone. The bars labeled none depict results from neurons treated with ddA alone, compared with untreated controls. Asterisks indicate a significant change ( $p<0.05$ by Student's $t$ test) in the relevant current component associated with the indicated peptide treatments. Note that both PACAP3 8 and PACAP27 selectively reduced the $\alpha 7$-AChR component without affecting the $\alpha 3^{*}$-AChR component. 
A

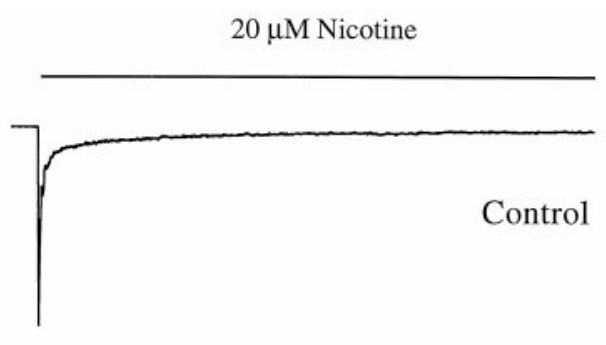

B

$20 \mu \mathrm{M}$ Nicotine
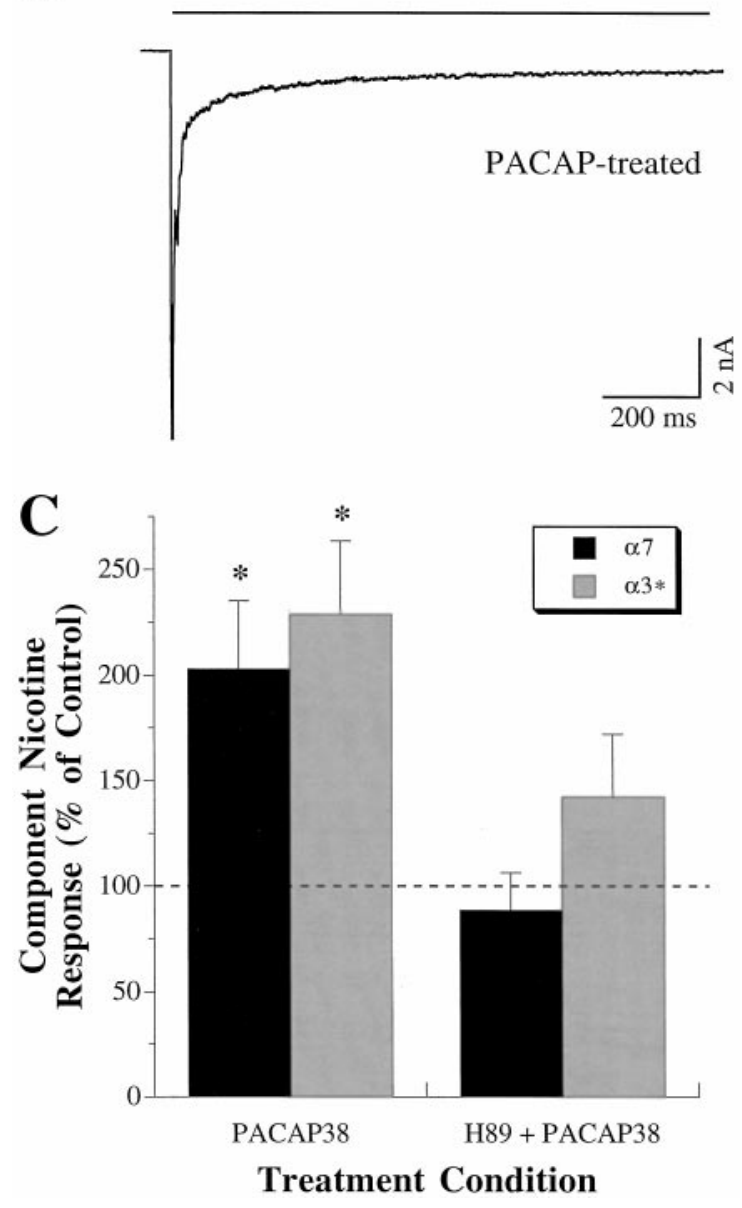

Figure 2. When AC activity is left intact, PACAP enhances $\alpha 7$ - and $\alpha 3^{*}$-AChR currents by a mechanism requiring PKA. Representative whole-cell currents induced by fast perfusion with $20 \mu \mathrm{M}$ nicotine are shown from a control neuron $(A)\left(C_{\mathrm{m}}=29 \mathrm{pF}\right)$ and a neuron treated with $100 \mathrm{~nm}$ PACAP38 for 8 min before testing $(B)\left(C_{\mathrm{m}}=27 \mathrm{pF}\right)$. Neurons were held at $-70 \mathrm{mV}$ and not pretreated with ddA. Calibration bars in $B$ apply to both records. The values of $I_{\mathrm{f}} / C_{\mathrm{m}}(\alpha 7$-AChRs $)$ and $I_{\mathrm{s}} / C_{\mathrm{m}}\left(\alpha 3^{*}-\right.$ AChRs) were -174 and $-40 \mathrm{pA} / \mathrm{pF}$, respectively, for the neuron in $A$, and -288 and $-133 \mathrm{pA} / \mathrm{pF}$, respectively, for the neuron in $B$. C, Summary of $\alpha 7$ - and $\alpha 3^{*}$-AChR component responses to $20 \mu \mathrm{M}$ nicotine (black and gray bars, respectively) after $10 \mathrm{~min}$ incubation in $100 \mathrm{nM}$ PACAP38 (left). PACAP treatment enhanced both $\alpha 7$ - and $\alpha 3^{*}$-AChR currents by approximately twofold (asterisks above bars indicate $p<0.02$ ). When neurons were pretreated for $5 \mathrm{~min}$ with $10 \mu \mathrm{M} \mathrm{H}-89$ to inhibit PKA activity (right), however, treatment with PACAP38 failed to change subsequent $\alpha 7$ - or $\alpha 3^{*}$-AChR components $(p>0.1)$. Results were obtained for eight neurons for each condition and are expressed as a percentage (mean \pm SEM) of the $\alpha 7$ - and $\alpha 3^{*}$-AChR component nicotine responses obtained from control neurons (exposed to neither PACAP nor H-89) tested in parallel (dashed line).

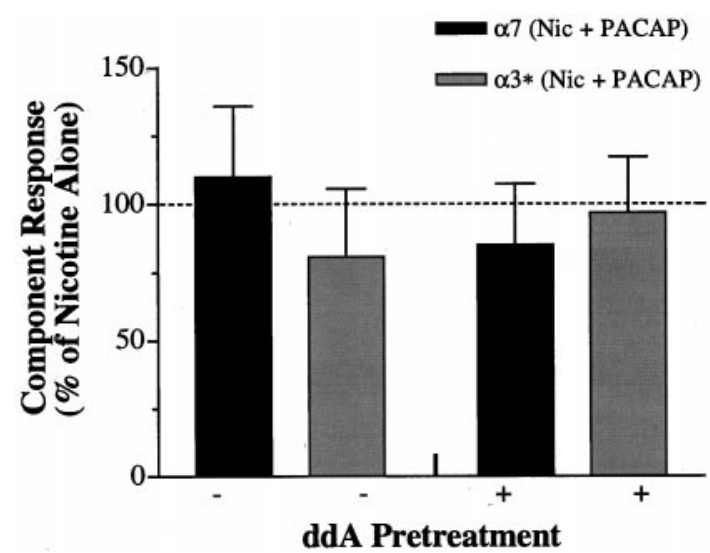

Figure 3. Absence of any immediate AChR modulation by PACAP. $\alpha 7$ and $\alpha 3^{*}$-AChR responses (black and gray bars, respectively) to $20 \mu \mathrm{M}$ nicotine coapplied with $100 \mathrm{~nm}$ PACAP38 $(\mathrm{Nic}+\mathrm{PACAP})$ are compiled relative to responses from neurons tested in parallel that were challenged with $20 \mu \mathrm{M}$ nicotine alone (dashed line). Under such conditions, PACAP38 failed to detectably alter the AChR responses $(p>0.1$ for each bar) either when AC was left intact (-) or after AC inhibition (+) by $10 \mathrm{~min}$ pretreatment with $200 \mu \mathrm{M} \mathrm{ddA}(n=7-10$ neurons tested with $\mathrm{Nic}+$ PACAP or with Nic alone for each condition).

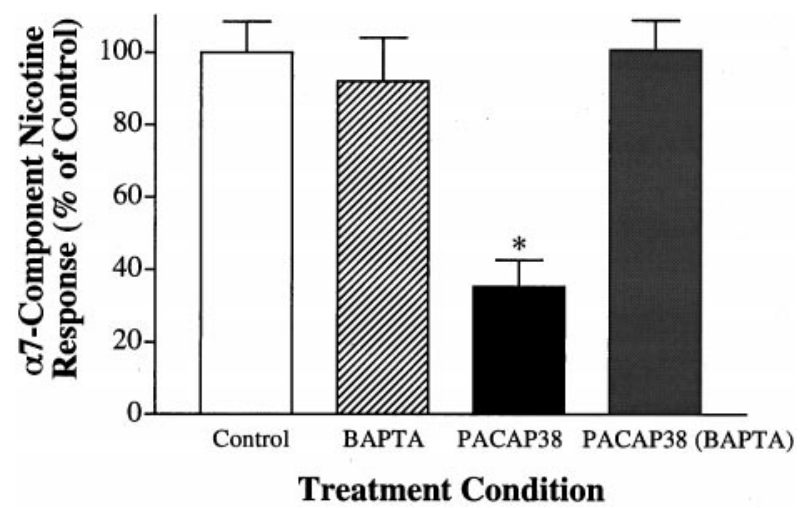

Figure 4. PACAP inhibits $\alpha 7$-AChRs by a mechanism involving $\left[\mathrm{Ca}^{2+}\right]_{\mathrm{i}}$ mobilization. Ciliary ganglion neurons were pretreated with ddA (200 $\mu \mathrm{M})$ for 2-7 min to block AC activity, subjected to the indicated treatments, and subsequently tested for nicotine responses as described in the legend for Figure 1. Control neurons received no PACAP38 treatment (unfilled bar) and displayed $\alpha 7$-AChR responses $\left(I_{\mathrm{f}} / C_{\mathrm{m}}\right)$ of $217 \pm 18$ $\mathrm{pA} / \mathrm{pF}(n=6)$. PACAP38 treatment $(100 \mathrm{~nm}, 10 \mathrm{~min})$ inhibited $\alpha 7-$ AChRs (black bar), reducing $I_{\mathrm{f}} / C_{\mathrm{m}}$ in this experiment by nearly $70 \%$ $\left({ }^{*} p<0.001\right)$. When the same PACAP38 treatment was preceded by dialysis with $10 \mathrm{~mm}$ BAPTA, however, it failed to inhibit $\alpha 7$-AChRs ( gray bar). Each bar represents the mean ( \pm SEM) $\alpha 7$-AChR component nicotine response for each condition ( $n=6-8$ neurons), expressed as a percentage of that obtained from ddA controls from the same two experiments. $\alpha 7-\mathrm{AChR}$ responses obtained from three neurons dialyzed with BAPTA but not treated with PACAP (striped bar) were not detectably different from control neurons dialyzed with normal intracellular solution. $\alpha 3 *-\mathrm{AChR}$ responses were not significantly changed by the treatments $(p>0.1$; data not shown).

Fluo-3AM before peptide exposure displayed a pale blue-green fluorescence associated with basal calcium levels. During bath perfusion with $100 \mathrm{~nm}$ PACAP38, the fluorescence intensity gradually increased in $85 \%$ of neurons tested (Fig. $5 A$, Table 2), reaching a plateau approximately 1.5 -fold above basal levels within 30-90 sec. No change was detected in neurons exposed to recording solution lacking the peptide (data not shown). The increased fluorescence response to PACAP38 application was 

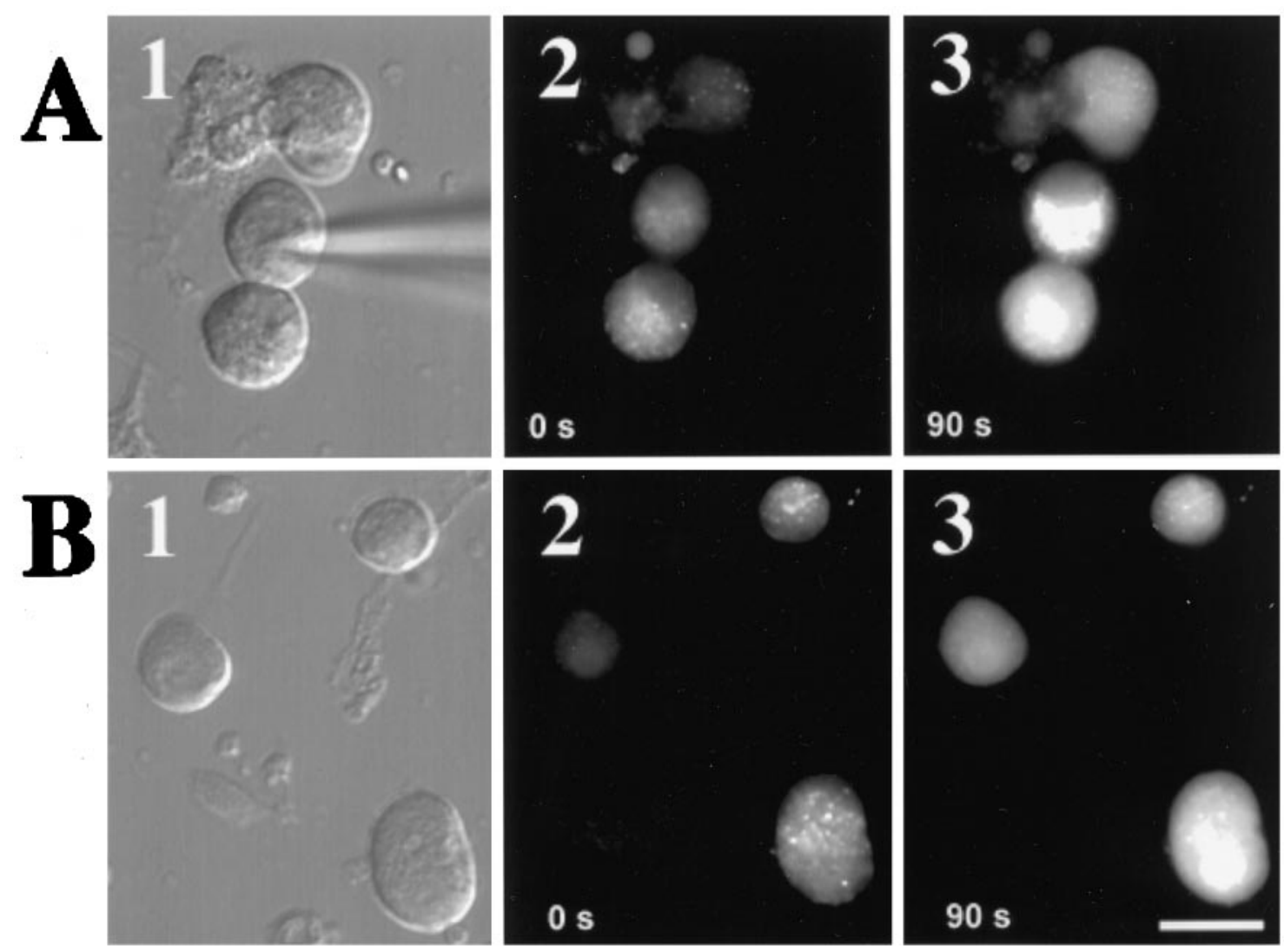

Figure 5. PACAP mobilizes intracellular $\mathrm{Ca}^{2+}$ stores. $A$, Application of PACAP38 elevates $\left[\mathrm{Ca}^{2+}\right]_{\mathrm{i}}$ in both ddA-dialyzed and intact ciliary ganglion neurons. A1, Image obtained using bright-field optics that depicts a field of three neurons bathed in normal recording solution. A whole-cell recording has been established on the center neuron, causing its intracellular contents to be dialyzed with pipette solution containing $200 \mu \mathrm{M}$ ddA to inhibit AC. $A 2, A 3$, The same field as in $A 1$ showing images obtained using epifluorescence optics taken 0 and 90 sec after initiating bath perfusion with normal recording solution containing $100 \mathrm{~nm}$ PACAP38. Note the increased Fluo-3AM fluorescence in each of the three neurons. $B$, PACAP38 elevates $\left[\mathrm{Ca}{ }^{2+}\right]_{\mathrm{i}}$ in ciliary ganglion neurons bathed in recording solution lacking added $\mathrm{Ca}^{2+} . B 1$, Bright-field optics. $B 2, B 3$, Epifluorescence images taken 0 and 90 sec after initiating perfusion with $0 \mathrm{Ca}^{2+}$ recording solution containing $100 \mathrm{nM}$ PACAP38. Scale bar (shown in $B 3$ for all panels): $20 \mu \mathrm{m}$.

Table 2. Properties of $\left[\mathrm{Ca}^{2+}\right]_{i}$ mobilization induced by PACAP38

\begin{tabular}{llllll} 
Intracellular dialysis & $\begin{array}{c}\text { Control } \\
( \pm \text { ddA })\end{array}$ & BAPTA & U-73122 & Heparin & $\begin{array}{l}\text { Ruthenium } \\
\text { Red }\end{array}$ \\
\hline Detectable $\left[\mathrm{Ca}^{2+}\right]_{\mathrm{i}}$ increase $(\%$ of neurons) & 85 & $29^{*}$ & $25^{*}$ & $11^{*}$ & 86 \\
$95 \%$ confidence interval $( \pm \%)$ & 8 & 33 & 30 & 20 & 26 \\
$n$ & 67 & 7 & 8 & 9 & 7
\end{tabular}

PACAP38-induced increases in $\left[\mathrm{Ca}^{2+}\right]_{\mathrm{i}}$ were detected using Fluo-3AM imaging as described in Materials and Methods and Figure 5. For each condition, the percentage of ciliary ganglion neurons $(n=7-67)$ responding to PACAP38 application ( $\pm 95 \%$ confidence interval) with a detectable increase in Fluo-3AM fluorescence $(\sim 15 \%$ above basal) is indicated. The percentage of responsive control neurons not subjected to dialysis was indistinguishable from that for control neurons dialyzed with $200 \mu \mathrm{M}$ ddA (see Results), and results for both data sets are pooled ( \pm ddA). Test neurons were dialyzed with intracellular solution containing BAPTA $(10 \mathrm{mM}), \mathrm{U}-73122(100 \mathrm{nM})$, heparin $(300 \mu \mathrm{M})$, or Ruthenium Red $(10 \mu \mathrm{M})$ for $1-2$ min before bath perfusion with $100 \mathrm{~nm}$ PACAP38. Asterisks indicate a significant difference in the percentage of PACAP38-responsive neurons $(p<0.05)$ in the test populations compared with controls $( \pm$ ddA).

indicative of elevated $\left[\mathrm{Ca}^{2+}\right]_{i}$ because it was absent in most neurons dialyzed with $10 \mathrm{~mm}$ BAPTA to buffer $\left[\mathrm{Ca}^{2+}\right]_{\mathrm{i}}$. PACAPdependent activation of $\mathrm{AC}$ was not a requirement for elevation of $\left[\mathrm{Ca}^{2+}\right]_{\mathrm{i}}$ levels because the proportion of neurons responding to PACAP application was indistinguishable in neurons dialyzed with ddA $(89 \%, n=9)$ and in adjacent neurons not exposed to the inhibitor $(84 \%, n=58)$. In contrast, PACAP-dependent activation of PLC was required because the fraction of PACAPresponsive neurons was reduced to $25 \%$ when neurons were dialyzed with U-73122 to block PLC (Basille et al., 1995; Barnhart et al., 1997) and subsequent $\mathrm{IP}_{3}$ formation. PACAP-induced elevation of $\left[\mathrm{Ca}^{2+}\right]_{\mathrm{i}}$ similar to that obtained in normal perfusion solution was observed in the absence of added $\mathrm{Ca}^{2+}$ (Fig. 5B), indicating that the $\left[\mathrm{Ca}^{2+}\right]_{\mathrm{i}}$ arose from an intracellular store. To localize the source of the $\mathrm{Ca}^{2+}$ released by PACAP application, we examined the effects of $\mathrm{IP}_{3}$ or ryanodine receptor blockers applied to neurons via the patch pipette. Inclusion of heparin in the patch pipette to block $\mathrm{IP}_{3}$ receptors (Ghosh et al., 1988; Rawlings et al., 1994) reduced the fraction of neurons responding to PACAP with a detectable increase in $\left[\mathrm{Ca}^{2+}\right]_{\mathrm{i}}$ to $11 \%$, whereas 
Ruthenium Red, a ryanodine receptor blocker (Kano et al., 1995), was without effect (Table 2). Thus consistent with its $\mathrm{Ca}^{2+}$-dependent ability to inhibit $\alpha 7-\mathrm{AChRs}$, imaging experiments indicate that PACAP38 mobilizes $\left[\mathrm{Ca}^{2+}\right]_{\mathrm{i}}$ from an $\mathrm{IP}_{3^{-}}$ sensitive store by using a PLC-dependent signaling pathway.

\section{PACAP increases inositol phosphate turnover via PLC}

We directly tested the ability of PACAP38 and related peptides to activate the PLC-dependent signaling pathway in ciliary ganglion neurons using IP turnover assays (Fig. 6). After 16-24 hr incubation with ${ }^{3} \mathrm{H}$-inositol, exposure to PACAP38 or PACAP27 caused a dose-dependent release of ${ }^{3} \mathrm{H}$-IPs (Fig. 6A). Maximal ${ }^{3} \mathrm{H}$-IP release (approximately two- to threefold above basal) was obtained with 100 nm PACAP38 or PACAP27, the same concentration that inhibited $\alpha 7$-AChR currents in the electrophysiological assays (Fig. 1, Table 1). Peptide potencies were determined from the concentrations required to produce $50 \%$ of maximum ${ }^{3} \mathrm{H}$-I Ps release $\left(\mathrm{EC}_{50}\right) . \mathrm{EC}_{50}$ values were $0.2 \pm 0.1 \mathrm{nM}(n=5)$ for PACAP38 and $2.4 \pm 1.1 \mathrm{nM}(n=3)$ for PACAP27. The 12-fold higher potency of PACAP38 over PACAP27 $(p<0.02)$ for stimulating IP turnover in ciliary ganglion neurons contrasts with their similar potencies for stimulating cAMP production in the neurons $\left(\mathrm{EC}_{50}=0.5 \mathrm{nM}\right.$ and $1.1 \mathrm{nM}$, respectively (Margiotta and Pardi, 1995). Consistent with our electrophysiological findings (Fig. 1), $100 \mathrm{~nm}$ VIP failed to stimulate IP turnover and did so only marginally even when applied at $1 \mu \mathrm{M}$. Glucagon, a PACAPrelated peptide with low affinity for the type I receptor, was ineffective even at $1 \mu \mathrm{M}$. A similar pharmacology indicative of PACAP specificity and differential coupling of PACAP38 and PACAP27 to AC and PLC transduction pathways is observed for native type I receptors on PC12 cells (Deutsch and Sun, 1992) and for cloned type I receptors expressed in LLC-PK1 cells (Spengler et al., 1993). Because of this ability to couple to two transduction cascades, it was important to determine the relative importance of the PLC and AC effectors for increasing IP production. When neurons were preincubated with U-73122 to inhibit PLC and then challenged with PACAP, there was a 50\% reduction in the specific peptide-induced release of ${ }^{3} \mathrm{H}-\mathrm{IPs}$ (Fig. $6 B)$. In contrast, preincubation with ddA to inhibit AC did not detectably alter basal or PACAP-induced release of ${ }^{3} \mathrm{H}$-IPs. These findings demonstrate that PACAP38 increases IP turnover in ciliary ganglion neurons at the same concentration that inhibits $\alpha 7$-AChRs and increases $\left[\mathrm{Ca}^{2+}\right]_{\mathrm{i}}$ levels. The similar pharmacological profile of both the increased IP turnover and $\left[\mathrm{Ca}^{2+}\right]_{i}$ levels indicates that PACAP type I receptors couple via PLC to increase IP turnover and $\mathrm{Ca}^{2+}$ release from an $\mathrm{IP}_{3}$-sensitive internal store.

\section{IP turnover-dependent $\mathrm{Ca}^{2+}$ release is required for $\alpha 7-A C h R$ inhibition}

We next sought to determine whether activation of the PLCdependent pathway producing IP turnover and $\left[\mathrm{Ca}^{2+}\right]_{\mathrm{i}}$ release is required for the $\alpha 7$-AChR inhibition produced by PACAP. This was accomplished by dialyzing neurons with reagents that interfere with or mimic activation of the PLC signaling pathway via the patch pipette before and during exposure to PACAP38 (Fig. 7). To examine a requirement for PLC, neurons were pretreated with ddA, then dialyzed with intracellular solution containing the PLC inhibitor U-73122. Because it prevented the PACAP-induced increase in $\left[\mathrm{Ca}^{2+}\right]_{\mathrm{i}}$ (Table 2), dialysis with $100 \mathrm{nM}$ U-73122 also prevented PACAP38-induced inhibition of $\alpha 7$-AChRs. The PACAP-induced, PLC-dependent inhibition of $\alpha 7$-AChRs is
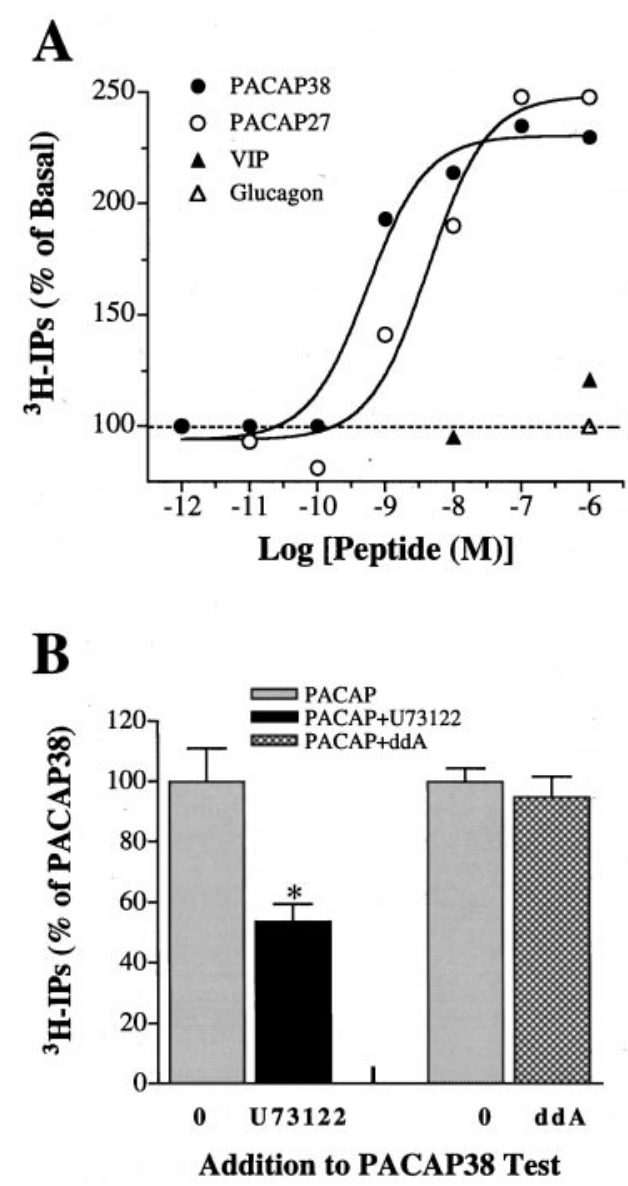

Figure 6. PACAP increases IP turnover via PLC. A, PACAP38 (O) and PACAP27 (O) stimulate IP production in a dose-dependent manner. Ciliary ganglion neurons were incubated overnight in media containing 2 $\mu \mathrm{Ci} / \mathrm{ml}$ myo- $\left[{ }^{3} \mathrm{H}\right]$ inositol and then challenged with the indicated concentrations of PACAP for 40-60 min. Membrane lipids were then extracted, and ${ }^{3} \mathrm{H}$-IPs were measured as described in Materials and Methods. For each peptide concentration, the results are expressed as the percentage increase in ${ }^{3} \mathrm{H}$-IPs for treated neurons above the basal levels obtained from untreated neurons. The assays were performed in duplicate, with each curve representing a single experiment, and the results were fitted to a sigmoidal dose-response curve (solid lines) by nonlinear regression $\left(r^{2}>0.97\right)$. For the PACAP38 and PACAP27 data depicted, $\mathrm{EC}_{50}$ values representing the concentrations required for half-maximal IP production were 0.5 and $4.2 \mathrm{nM}$, and maximal peptide-induced ${ }^{3} \mathrm{H}$-IP release above basal levels were 230 and $249 \%$, respectively. Similar results were obtained in four other experiments with PACAP38 and in two experiments with PACAP27. VIP $(\boldsymbol{\Delta})$ failed to increase ${ }^{3} \mathrm{H}-\mathrm{IP}$ release at $100 \mathrm{nM}$ and induced only a nominal $20 \%$ increase $(p<0.1 ; n=3)$ at $1 \mu \mathrm{M}$, whereas $1 \mu \mathrm{M}$ Glucagon $(\triangle)$ produced no detectable change $(n=2)$. $B$, PACAP38 couples via PLC signaling to stimulate IP turnover. IPs were measured from neuron cultures after preincubation with myo- $\left[{ }^{3} \mathrm{H}\right]$ inositol and treatment with $1 \mu \mathrm{M}$ PACAP38 as in $A$ (gray bars) and compared with parallel cultures treated with $1 \mu \mathrm{M}$ PACAP38 plus $200 \mu \mathrm{M}$ ddA or $1 \mu \mathrm{M}$ U-73122 to block AC or PLC (black and hatched bars), respectively. Results depicted were obtained from quadruplicate well assays from two to three experiments and indicate ${ }^{3} \mathrm{H}$-IP release (mean \pm SEM) as a percentage of that obtained after treatment with PACAP38 alone. Note that U-73122 significantly reduced PACAP38-induced IP turnover $\left({ }^{*} p<0.01\right)$, whereas ddA was ineffective $(p>0.1)$.

likely to require increased IP turnover, leading to $\mathrm{IP}_{3}$ production. Thus dialysis with a high-affinity $\mathrm{IP}_{3}$ receptor agonist $\left(\mathrm{HA}-\mathrm{IP}_{3}\right)$ mimicked the inhibition produced by PACAP38, whereas application of a weak $\mathrm{IP}_{3}$ agonist $\left(\mathrm{LA}-\mathrm{IP}_{3}\right)$ was ineffective in detectably changing $\alpha 7$-AChR currents. Further downstream, $\mathrm{IP}_{3^{-}}$ 


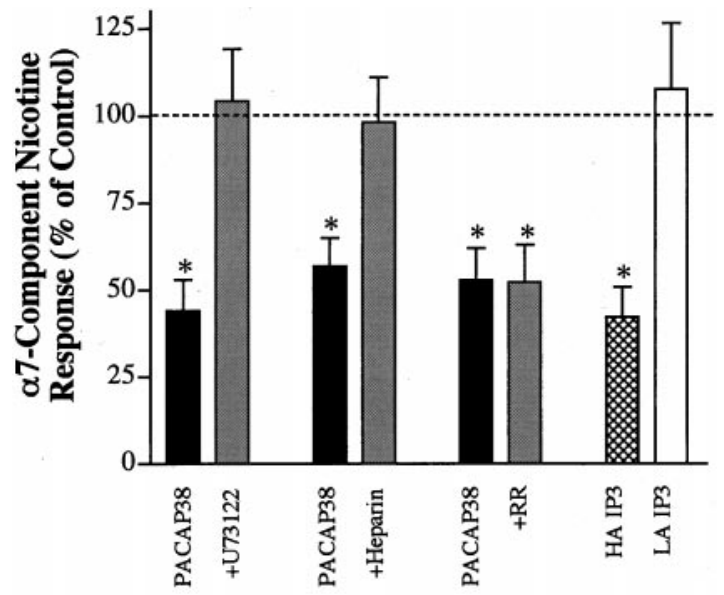

Treatment Condition

Figure 7. PLC-dependent signaling is required for PACAP38-induced inhibition of $\alpha 7$-AChRs. Ciliary ganglion neurons were assayed for $\alpha 7$ $\mathrm{AChR}$ currents in response to fast perfusion with $20 \mu \mathrm{M}$ nicotine as described in Materials and Methods and in the legend for Figure 1. Results are expressed as a percentage (mean \pm SEM) of the $\alpha 7$-AChR component response $\left(I_{\mathrm{f}} / C_{\mathrm{m}}\right)$ under the indicated test conditions, relative to that from ddA-pretreated control neurons tested in parallel that were not treated with PACAP38 (100\%; dashed line). The PACAP38-induced reduction of $\alpha 7$-AChR responses (black bars; $p<0.02$ ) was reversed by dialysis for $1-2$ min with U-73122 $(100 \mathrm{nM} ; p>0.1)$ or heparin $(300 \mu \mathrm{M}$; $p>0.1$ ) before PACAP38 treatment (gray bars) but was unaffected by dialysis with Ruthenium Red $(10 \mu \mathrm{M} ; p<0.002)$. Results for each condition were based on measurements from six control neurons, six neurons treated with PACAP38 alone, and six neurons treated with PACAP38 plus $(+)$ the indicated inhibitor. The PACAP38-induced inhibition $\alpha 7$-AChR responses was mimicked by dialysis with HA-IP3 but not by LA-IP3 (each at $2 \mu \mathrm{M}$; hatched and unfilled bars, respectively; $n=6$ neurons for each). *Significant difference from control neurons tested in parallel (dashed line).

dependent $\mathrm{Ca}^{2+}$ mobilization is also important for inhibition of $\alpha 7$-AChRs. Inclusion of heparin in the patch pipette $(300 \mu \mathrm{M})$ to block the $\mathrm{IP}_{3}$ receptor-mediated increase in $\left[\mathrm{Ca}^{2+}\right]_{\mathrm{i}}$ (Table 2) also blocked the ability of PACAP38 to inhibit $\alpha 7$-AChRs whereas inclusion of Ruthenium Red was ineffective. These findings demonstrate that PACAP's $\mathrm{Ca}^{2+}$-dependent inhibition of $\alpha 7$-AChRs involves PACAP type I receptor activation of PLC, IP turnover, and $\mathrm{IP}_{3}$-sensitive $\mathrm{Ca}^{2+}$ release.

\section{DISCUSSION}

The preceding results elucidate dual signal cascades that differentially modulate AChRs on chick ciliary ganglion neurons (Fig. 8). Previous experiments demonstrated that PACAP type I receptors couple via increased AC activity and cAMP production to enhance AChR function, but they also suggested a second signaling pathway, unmasked after blocking AC, that reduced AChR function (Margiotta and Pardi, 1995). The goals of the present study were to characterize the inhibitory pathway and determine the relevant AChRs affected. We now report that PACAP type I receptors on the neurons also couple to a parallel PLC-dependent signaling pathway involving IP turnover and $\mathrm{IP}_{3}$-stimulated $\mathrm{Ca}^{2+}$ release that inhibits $\alpha 7$-AChRs without detectably affecting $\alpha 3 *$-AChRs. Supportive evidence for these conclusions emerges from three interdependent sets of experiments. First, electrophysiological studies demonstrated that PACAP reduced $\alpha 7-A C h R$ currents when AC was suppressed. Second, biochemical and $\mathrm{Ca}^{2+}$ imaging experiments revealed

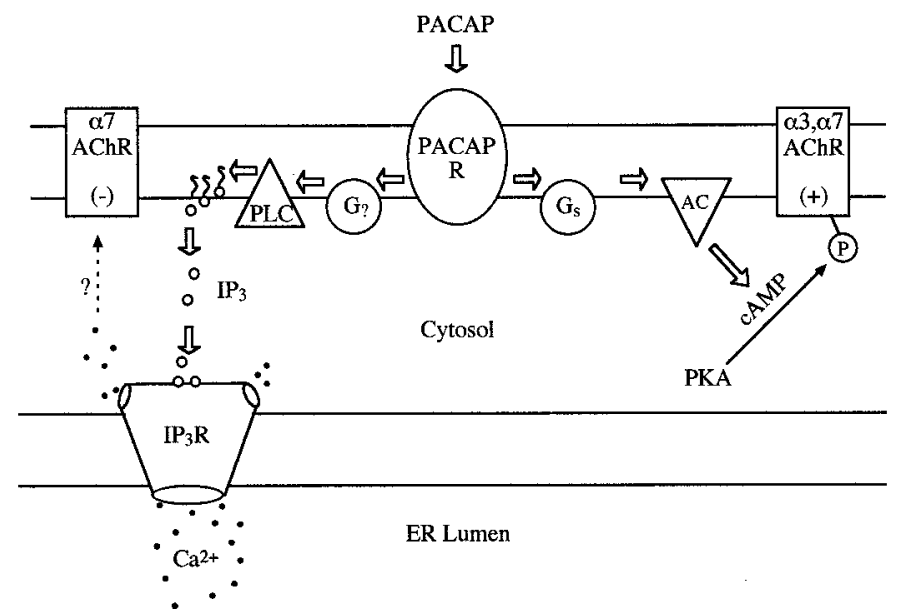

Figure 8. PACAP type I receptors couple through AC- or PLCdependent signaling cascades to differentially regulate $\alpha 7$ - and $\alpha 3^{*}$-AChR function. See Results for details.

that PACAP activates the PLC pathway, eliciting PLC-dependent IP turnover, $\mathrm{IP}_{3}$ production, and $\mathrm{Ca}^{2+}$ release from an $\mathrm{IP}_{3^{-}}$ sensitive store. Third, pharmacological experiments demonstrated that reagents that interfere with the PLC cascade block the ability of PACAP to inhibit $\alpha 7$-AChRs.

Interpreting the electrophysiological results depended on assigning currents induced by fast nicotine perfusion to either $\alpha 7$ or $\alpha 3^{*}$-AChRs. The appropriateness of such assignments has already been established (Zhang et al., 1994; Blumenthal et al., 1999 ) but warrants brief discussion. First, the fitted $\alpha 7$ - and $\alpha 3^{*}$-AChR current amplitudes $\left(I_{\mathrm{f}}\right.$ and $\left.I_{\mathrm{s}}\right)$ and associated decay time constants $\left(\tau_{\mathrm{f}}, \tau_{\mathrm{i}}\right.$, and $\left.\tau_{\mathrm{s}}\right)$ obtained in the present study (Fig. 1 , Table 1) are in good agreement with those previously reported for the same neurons (Zhang et al., 1994). Second, the initial fast $\alpha 7$-AChR component was independently identified because $I_{\mathrm{f}}$ was selectively abolished by $\alpha$ Bgt (Fig. $1 B$ ). Third, the smaller, more slowly decaying current component $\left(I_{\mathrm{s}}\right)$ was insensitive to $\alpha \mathrm{Bgt}$ and therefore unlikely to represent a contribution from $\alpha 7$ AChRs in significant numbers. After identifying $I_{\mathrm{f}}$ and $I_{\mathrm{s}}$ as arising primarily from $\alpha 7$ - and $\alpha 3^{*}$-AChRs, respectively, we observed differential effects on the $\alpha 7$ - or $\alpha 3^{*}$-AChRs after PACAP receptor occupation that depended on the status of the AC signaling pathway. Because PACAP type I receptors activate two signal cascades in other systems (Rawlings, 1994), the selective inhibition of $\alpha 7$-AChRs (Fig. 1) was presumed to result from unmasked activation of another signal cascade, possibly one requiring PLC. This hypothesis was initially supported by observations that ddA blocks AC-dependent production of cAMP (Margiotta and Pardi, 1995) and that without ddA pretreatment, PACAP enhances $\alpha 7$ - and $\alpha 3^{*}$-AChR currents in a PKAdependent manner (Fig. 2). Further support emerged by documenting a PLC-dependent pathway in the neurons required for PACAP-induced $\alpha 7$-AChR inhibition.

We showed previously that ciliary ganglion neurons express PACAP type I receptors that stimulate cAMP production (Margiotta and Pardi, 1995). The receptors have nanomolar affinities for PACAP38 and PACAP27 and 500- to 1000-fold lower affinity for VIP. The same ligands displayed potencies for stimulating cAMP production that paralleled their relative affinities. Studies with recombinant PACAP receptors have demonstrated that type I receptor isoforms, featuring seven membrane-spanning domains 
characteristic of G-protein-coupled receptors, can activate PLCdependent (for review, see Spengler et al., 1993; Rawlings, 1994) as well as AC-dependent (Hashimoto et al., 1993; Pisegna and Wank, 1993) signal cascades. Other G-protein-coupled receptors such as those for calcitonin, parathyroid hormone, and thyrotropin are known to activate both AC and PLC cascades (for review, see Deutsch and Sun, 1992; Spengler et al., 1993). PACAP receptors on ciliary ganglion neurons also couple through PLC, because high-affinity PACAP receptor ligands induced $\left[\mathrm{Ca}^{2+}\right]_{\mathrm{i}}$ mobilization (Fig. 5) and IP turnover (Fig. 6) even with AC activity blocked. PACAP38, PACAP27, and VIP had potencies for IP production $\left(\mathrm{EC}_{50}=0.2,2.4, \gg 1000 \mathrm{nM}\right.$, respectively) that were comparable to those obtained previously for recombinant type I receptors expressed in cell lines (Spengler et al., 1993; Rawlings, 1994) and native PACAP type I receptors on PC12 cells (Deutsch and Sun, 1992). We presume that the lower potency of PACAP27 in stimulating IP production was not reflected in our electrophysiological assays using PACAP38 or PACAP27 because the $100 \mathrm{nM}$ concentrations used produced maximal IP turnover in both cases.

In the present experiments, VIP $(1 \mu \mathrm{M})$ did not significantly inhibit $\alpha$-AChRs (Fig. 1) or stimulate IP turnover (Fig. 6), although this concentration occupies $\sim 50 \%$ of the type I receptors on the neurons and stimulates substantial cAMP production (Margiotta and Pardi, 1995). The negligible potency of VIP in stimulating IP production is consistent with results from native and recombinant PACAP type I receptors cited above. In such cases, the low-affinity VIP binding to PACAP type I receptors might be inadequate to provide sufficient activation of PLC. Our previous finding that, after ddA pretreatment, $1 \mu \mathrm{M}$ VIP reduced total ACh sensitivity by 50\% (Margiotta and Pardi, 1995) contrasts with its nominal $20 \%$ inhibition of $\alpha 7$-AChRs seen here. The difference in results is likely to be quantitative and reflect both the different agonists and application methods used and the marginal ability of VIP to activate PLC. In accord with the ability of PACAP38 to activate a PLC cascade in ciliary ganglion neurons, application of the peptide also led to increased $\left[\mathrm{Ca}^{2+}\right]_{\mathrm{i}}$ levels assessed by direct imaging (Table 2 ). The $\left[\mathrm{Ca}^{2+}\right]_{i}$ mobilization was verified as originating from an intracellular store because it persisted with no added $\mathrm{Ca}^{2+}$ in the extracellular solution. As expected for a response arising from IP turnover and subsequent $\mathrm{IP}_{3}$ production, the $\left[\mathrm{Ca}^{2+}\right]_{\mathrm{i}}$ store was verified to be $\mathrm{IP}_{3}$ sensitive because heparin, a classic $\mathrm{IP}_{3}$ receptor antagonist, blocked the response, whereas Ruthenium Red, a ryanodine receptor antagonist, did not. In addition, the ability of PACAP38 to increase IP turnover and $\left[\mathrm{Ca}^{2+}\right]_{\mathrm{i}}$ levels in the neurons was specific to the PLC signal pathway because PLC inhibition reduced peptide-induced IP and $\mathrm{Ca}^{2+}$ production, whereas AC inhibition was ineffective (Figs. 5, 6). Taken together, the simplest scheme that can explain our findings is that PACAP receptors on ciliary ganglion neurons belong to a single type I class that can couple to both AC and PLC signaling pathways (Fig. 8).

If a PLC-dependent signal cascade were required for $\alpha 7$-AChR inhibition, then reagents applied via the patch pipette that perturb critical elements or products of the cascade should block the inhibition. All of the tests we performed satisfied this prediction, and support the proposed scheme depicted in Figure 8. First, reducing PLC activity with U-73122 blocked the ability of PACAP38 to not only raise $\left[\mathrm{Ca}^{2+}\right]_{\mathrm{i}}$ but also to inhibit $\alpha 7$-AChRs. Second, the production of $\mathrm{IP}_{3}$ was critical because HA-IP $\mathrm{P}_{3}$ mimicked the PACAP-induced inhibition of $\alpha 7$-AChRs, whereas the low-affinity $\mathrm{IP}_{3}$ receptor analog $\left(\mathrm{LA}-\mathrm{IP}_{3}\right)$ was without effect.
Third, $\mathrm{IP}_{3}$-sensitive $\mathrm{Ca}^{2+}$ release was critical because dialysis with heparin blocked both PACAP-induced increase in $\left[\mathrm{Ca}^{2+}\right]_{\mathrm{i}}$ and resultant inhibition of $\alpha 7$-AChRs. Last, the $\left[\mathrm{Ca}^{2+}\right]_{\mathrm{i}}$ that is produced is required because chelating $\mathrm{Ca}^{2+}$ with application of BAPTA abolished PACAP's subsequent ability to inhibit $\alpha 7$ AChRs (Fig. 4). Taken together, these results strongly support the hypothesis that the PLC pathway activated by PACAP inhibits $\alpha 7$-AChRs by a process requiring $\mathrm{Ca}^{2+}$ release from an $\mathrm{IP}_{3}$ dependent intracellular store.

How the PACAP-induced increase in $\left[\mathrm{Ca}^{2+}\right]_{\mathrm{i}}$ might inhibit $\alpha 7-\mathrm{AChR}$ function is still an open question. A direct $\left[\mathrm{Ca}^{2+}\right]_{\mathrm{i}}$ effect on $\alpha 7$-AChRs, however, such as that implicated for M-type $\mathrm{K}^{+}$channels (Selyanko and Brown, 1996), seems unlikely. Although previous studies showed that increasing extracellular $\mathrm{Ca}^{2+}$ inhibits neuronal AChRs, the effect does not involve a concomitant increase in $\left[\mathrm{Ca}^{2+}\right]_{\mathrm{i}}$ (Amador and Dani, 1995). In addition, elevating $\left[\mathrm{Ca}^{2+}\right]_{i}$ in neuron-like chromaffin cells by depolarization did not reduce subsequent nicotinic AChR currents (Khiroug et al., 1998). Thus explanations for the selective inhibition of $\alpha 7$-AChRs are likely to involve indirect $\mathrm{Ca}^{2+}$ dependent mechanisms. One possibility is that increased $\left[\mathrm{Ca}^{2+}\right]_{\mathrm{i}}$ enhances the activity of phospholipase $\mathrm{A}_{2}$, a $\mathrm{Ca}^{2+}$-dependent enzyme (Kennedy, 1989; Mayer and Marshall, 1993), causing release of arachidonic acid (AA), which in turn inhibits $\alpha 7$ AChRs. Others have demonstrated that PACAP potentiates the release of glutamate-induced AA from cortical neurons (Stella and Magistretti, 1996). In addition AA (1 $\mu \mathrm{M})$ inhibited both native $\alpha 7$-AChRs on ciliary ganglion neurons and recombinant $\alpha 7$-AChRs expressed in Xenopus oocytes (Vijayaraghavan et al., 1995). Interestingly, the AA effect on ciliary ganglion neurons was specific for $\alpha 7$-AChRs because high concentrations were required to detectably inhibit a3*-AChRs. Another possibility may involve activation of a $\mathrm{Ca}^{2+}$-dependent phosphatase. One candidate is calcineurin, which antagonizes the effects of elevations in cAMP (Kurosawa, 1994) by facilitating the dephosphorylation of proteins phosphorylated by PKA (Yakel, 1997). Because $\alpha 7-$ and $\alpha 3^{*}$-AChRs are likely to be substrates for PKA-dependent phosphorylation (Vijayaraghavan et al., 1990; Moss et al., 1996) and their upregulation by cAMP is dependent on PKA activity (Fig. 2), $\alpha 7-\mathrm{AChR}$ inhibition could involve selective dephosphorylation by a $\mathrm{Ca}^{2+}$-dependent phosphatase.

Under normal conditions when PACAP type I receptors can couple to both PLC and AC, cAMP production is increased in the neurons, and both $\alpha 7$ - and $\alpha 3^{*}$-AChR currents are enhanced by a process requiring PKA (Figs. 2, 8). Whether the modulation is explained by PKA-dependent phosphorylation of AChRs alone, however, or requires additional intermediary steps and/or phosphorylation events still remains to be determined. Because PACAP38 is approximately equipotent for stimulating cAMP production and IP turnover in the neurons, the bias toward AChR enhancement via AC is not likely to involve second messenger production but instead may result from different abilities of the activated cascades to influence their downstream targets. Overall, the results demonstrate a remarkable flexibility in ciliary ganglion neurons for differentially modulating two AChR classes. At one level, the findings are consistent with PACAP's PLCdependent dampening of $\alpha 7-\mathrm{AChR}$ responses being a safety mechanism to counteract the $\alpha 7$ - and $\alpha 3^{*}$-AChR enhancement produced by concomitant AC activity. Other scenarios are also possible, however. For example, more selective inhibition of $\alpha 7$ AChRs could be achieved if the G-proteins presumed to couple PACAP type I receptors to their AC and PLC cascades were 
localized at $\alpha 3 *$ - versus $\alpha 7$-AChR synaptic sites, respectively, or if receptors for other neuropeptides were present on the neurons that couple specifically with the PLC cascade. Future efforts will be directed toward answering such questions.

\section{REFERENCES}

Alkondon M, Albuquerque EX (1993) Diversity of nicotinic acetylcholine receptors in rat hippocampal neurons. I. Pharmacological and functional evidence for distinct structural subtypes. J Pharmacol Exp Ther 265:1455-1473.

Amador M, Dani JA (1995) Mechanism for modulation of nicotinic acetylcholine receptors that can influence synaptic transmission. J Neurosci 15:4525-4532.

Barnhart DC, Sarosi GA, Mullholland MW (1997) PACAP-38 causes phospholipase $\mathrm{C}$-dependent calcium signaling in rat acinar cell line. Surgery 122:465-475.

Basille M, Gonzalez BJ, Desrues L, Demas M, Fournier A, Vaudry H (1995) Pituitary adenylate cyclase-activating polypeptide (PACAP) stimulates adenylate cyclase and PLC activity in rat cerebellar neuroblasts. J Neurochem 65:1318-1324.

Berridge MJ (1993) Inositol triphosphate and calcium signaling. Nature 361:315-326.

Berridge MJ (1997) Elementary and global aspects of calcium signaling. J Physiol (Lond) 499:291-306.

Blumenthal EM, Shoop RD, Berg DK (1999) Developmental changes in the nicotinic responses of ciliary ganglion neurons. J Neurophysiol 81:111-120.

Conroy WG, Berg DK (1995) Neurons can maintain multiple classes of nicotinic acetylcholine receptors distinguished by different subunit compositions. J Biol Chem 270:4424-4431.

Cornell-Bell A, Finkbeiner S, Cooper M, Smith S (1990) Glutamate induces calcium waves in cultured astrocytes: long-range glial signaling. Science 247:470-473.

Couturier S, Bertrand D, Matter J-M, Hernandez M-C, Bertrand S, Millar N, Valera S, Barkas T, Ballivet M (1990) A neuronal nicotinic acetylcholine receptor subunit $(\alpha 7)$ is developmentally regulated and forms a homo-oligomeric channel blocked by $\alpha$-Btx. Neuron 5:847-496.

Cuevas J, Adams D (1996) VIP modulation of nAChR channels in rat intracardiac neurons. J Physiol (Lond) 493:503-515.

Deutsch PJ, Sun Y (1992) The 38-amino acid form of pituitary adenylate cyclase-activating polypeptide stimulates dual signaling cascades in PC12 cells and promotes neurite outgrowth. J Biol Chem 267:5108-5113.

Exton JH (1996) Regulation of phosphoinositide phospholipases by hormones, neurotransmitters, and other agonists linked to G-proteins. Annu Rev Pharmacol Toxicol 36:481-509.

Ghosh TK, Eis PS, Mullaney JM, Ebert CL, Gill DL (1988) Competitive, reversible and potent antagonism of inositol 1,4,5-triphosphateactivated calcium release by heparin. J Biol Chem 263:11075-11079.

Gurantz D, Harootunian AT, Tsien RY, Dionne VE, Margiotta JF (1994) VIP modulates neuronal nicotinic acetylcholine receptor function by a cyclic AMP-dependent mechanism. J Neurosci 14:3540-3547.

Hamill OP, Marty A, Neher E, Sakmann B, Sigworth FJ (1981) Improved patch-clamp techniques for high-resolution current recording from cells and cell-free membrane patches. Pflügers Arch 391:85-100.

Hashimoto H, Ishihara T, Shigemoto R, Mori K, Nagata S (1993) Molecular cloning and tissue distribution of a receptor for pituitary adenylate cyclase-activating polypeptide. Neuron 11:333-342.

Hille B (1992) G protein-coupled mechanisms and nervous signaling. Neuron 9:187-195.

Jonas P (1995) Fast application of agonists to isolated membrane patches. In: Single channel recording (Sakmann B, Necher E, eds). New York: Plenum.

Kano M, Garaschuk O, Verkhratsky A, Konnerth A (1995) Ryanodine receptor-mediated intracellular calcium release in rat cerebellar Purkinje neurons. J Physiol (Lond) 487.1:1-16.

Kao JPY, Harootunian AT, Tsien RY (1989) Photochemically generated cytosolic calcium pulses and their detection by Fluo-3. J Biochem 264:8179-8184.

Kennedy M (1989) Regulation of neuronal function by calcium. Trends Neurosci 112:417-420.

Khiroug L, Sokolova E, Giniatullin R, Afzalov R, Nistri A (1998) Re- covery from desensitization of neuronal nicotinic acetylcholine receptors of rat chromaffin cells is modulated by intracellular calcium through distinct second messengers. J Neurosci 18:2458-2466.

Kurosawa M (1994) Phosphorylation and dephosphorylation of proteins in regulating cellular function. J Pharmacol Toxicol Methods 31:135-139.

Levitan IB (1994) Modulation of ion channels by protein phosphorylation and dephosphorylation. Annu Rev Physiol 56:193-212.

Margiotta JF, Gurantz D (1989) Changes in the number, function and regulation of nicotinic acetylcholine receptors during neuronal development. Dev Biol 135:326-399.

Margiotta JF, Pardi D (1995) Pituitary adenylate cyclase-activating polypeptide type I receptors mediate cyclic AMP-dependent enhancement of neuronal acetylcholine sensitivity. Mol Pharmacol 48:63-71.

Margiotta JF, Berg DK, Dionne VE (1987) Cyclic AMP regulates the proportion of functional acetylcholine receptors on chick ciliary ganglion neurons. Proc Natl Acad Sci USA 84:8155-8159.

Mayer RJ, Marshall LA (1993) New insights on mammalian phospholipase A2: comparison of arachidonoyl-selective and nonselective enzymes. FASEB J 7:339-348.

Moss SJ, McDonald BJ, Rudhard Y, Schoepfer R (1996) Phosphorylation of the predicted major intracellular domains of the rat and chick nicotinic a7 subunit by cAMP-dependent protein kinase. Neuropharmacology 35:1023-1028.

Motulsky H (1995) Intuitive Biostatistics. New York: Oxford.

Pardi D, Margiotta JF (1996) PACAP receptor activation inhibits $\alpha 7$ containing neuronal acetylcholine receptors. Soc Neurosci Abstr 22:1522.

Pisegna JR, Wank SA (1993) Molecular cloning and functional expression of the pituitary adenylate cyclase-activating polypeptide type I receptor. Proc Natl Acad Sci USA 90:6345-6349.

Rathouz MM, Vijayaraghavan S, Berg DK (1995) Acetylcholine differentially affects intracellular calcium via nicotinic and muscarinic receptors on the same population of neurons. J Biol Chem 270:14366-14375.

Rawlings SR (1994) At the cutting edge: PACAP, PACAP receptors and intracellular signaling. Mol Cell Endocrinol 101:C5-C9.

Rawlings SR, Demaurex N, Schlegel W (1994) Pituitary adenylate cyclase-activating polypeptide increases $\left[\mathrm{Ca}^{2+}\right]_{\mathrm{i}}$ in rat gonadotrophs through an inositol triphosphate-dependent mechanism. J Biol Chem 269:5680-5686.

Ross EM (1989) Signal sorting and amplification through G-protein coupled receptors. Neuron 3:141-152.

Selyanko AA, Brown DA (1996) Intracellular calcium directly inhibits potassium $M$ channels in excised membrane patches from rat sympathetic neurons. Neuron 16:151-162.

Spengler D, Waeber C, Pantaloni C, Holsboer F, Bockaert J, Seeburg P, Journot L (1993) Differential signal transduction by five splice variants of the PACAP receptor. Nature 365:170-175.

Stella N, Magistretti PJ (1996) Vasoactive intestinal peptide (VIP) and pituitary adenylate cyclase-activating polypeptide (PACAP) potentiate the glutamate-evoked release of arachidonic acid from mouse cortical neurons. J Biol Chem 271:23705-23710.

Swope SL, Moss SJ, Blackstone CD, Huganir RL (1993) Phosphorylation of ligand-gated ion channels: a possible mode of synaptic plasticity. FASEB J 6:2514-2523.

Vernallis AB, Conroy WG, Berg DK (1993) Neurons assemble AChRs with as many as 3 kinds of subunits while maintaining subunit segregation among subtypes. Neuron 10:451-464.

Vijayaraghavan D, Schmid HA, Halvorsen SW, Berg DK (1990) Cyclic AMP-dependent phosphorylation of a neuronal acetylcholine receptor $\alpha$-type subunit. J Neurosci 10:3255-3262.

Vijayaraghavan S, Pugh PC, Zhang Z-W, Rathouz MM, Berg DK (1992) Nicotinic receptors that bind $\alpha$-bungarotoxin on neurons raise intracellular free $\mathrm{Ca}^{2+}$. Neuron 8:353-362.

Vijayaraghavan S, Huang B, Blumenthal EM, Berg DK (1995) Arachidonic acid as a possible negative feedback inhibitor of nicotinic acetylcholine receptors on neurons. J Neurosci 15:3679-3687.

Yakel JL (1997) Calcineurin regulation of synaptic function: from ion channels to transmitter release and gene expression. Trends Pharmacol Sci 18:124-134.

Zhang Z-W, Vijayaraghavan S, Berg DK (1994) Neuronal acetylcholine receptors that bind a-bungarotoxin with high affinity function as ligandgated ion channels. Neuron 12:167-177. 